\title{
REMATES Y VENTAS DE BIENES DESAMORTIZADOS EN COLOMBIA. EL CASO DEL ESTADO SOBERANO DE BOLÍVAR, 1861-1875
}

\section{AUCTIONS AND SALES OF DISENTAILED MORTMAIN IN COLOMBIA. THE CASE OF THE SOVEREIGN STATE OF BOLIVAR, 1861-1875}

\author{
Maribel de la Cruz Vergara* \\ Universidad de Cartagena, Cartagena de Indias, Colombia <mdelacruzv@unicartagena.edu.co>
}

Resumen. En este artículo se plantea el comportamiento de la desamortización de bienes de manos muertas en el Estado Soberano de Bolívar a través del análisis de los remates y ventas de bienes raíces, censo eclesiástico, y semovientes. Considerando que la desamortización fue una política nacional en los Estados Unidos de Colombia, se compara el Estado de Bolívar con cada uno de los estados soberanos que conformaban la Unión, con el fin de determinar, en primer lugar, la articulación entre la autonomía regional y las medidas centralizadas y, en segundo lugar, cómo se desamortizó y quiénes fueron los "nuevos" propietarios luego de esta reforma.

Palabras clave: bienes desamortizados; Colombia; Estado de Bolívar; ventas; remates.

Abstract. This article discusses the behavior of disentailment of mortmain in the Sovereign State of Bolivar through the analysis of auctions and real estate sales, ecclesiastical census, and livestock. Given that the disamortization was a national policy in the United States of Colombia, the Bolivar state is compared with each of the sovereign states that made up the Union in order to determine, first the link between regional autonomy and centralized measures, and secondly, how the disentailment of mortmain process was operated and who were the "new" owners after this reform.

Key words: disentailment of mortmain; Colombia; Bolivar State; sales; auctions.

Fecha de recepción: marzo de 2013. Fecha de aceptación: junio de 2013.

* Agradezco a los evaluadores anónimos sus sugerencias y comentarios que hicieron posible esta versión final.

Am. Lat. Hist. Econ., año 21, núm. 1, enero-abril, 2014, pp. 31-65 


\section{INTRODUCCIÓN}

$\mathrm{L}$

a desamortización ${ }^{1}$ de bienes de manos muertas fue un proceso de vieja data, que se inició desde la segunda mitad del siglo XVIII, tanto en España ${ }^{2}$ como en América, y que en Colombia encontró, a partir de 1860, las condiciones propicias para su ejecución. Esta adquirió dimensiones inesperadas para muchos, entre estos los conservadores y la población católica, la cual veía con cierto temor no sólo la expropiación de los bienes de la Iglesia, ${ }^{3}$ sino también la expulsión de muchos de sus miembros. En todo caso, las condiciones estaban dadas, pues se había adecuado el marco constitucional y jurídico necesario, los partidos políticos habían logrado acuerdos ${ }^{4}$ al respecto y el gobierno estaba a cargo de liberales radicales ${ }^{5}$ dispuestos a iniciar el proceso de desamortización de los bienes de la Iglesia. Para ello se basaban en el argumento de la modernización del Estado, la reestructuración de la propiedad y la redefinición de las relaciones Estado-Iglesia, factores que se convirtieron en el eje central de la política colombiana de la segunda mitad del siglo XIX.

Por las razones citadas, este tema ha ocupado a muchos investigadores, incluso desde el mismo siglo XIX; sin embargo, si se considera el impacto político y el de las nuevas apropiaciones económicas, encontramos que ha sido uno de los temas poco estudiados en la historiografía colombiana. En el contexto internacional -y específicamente en el caso de Amé-

${ }^{1}$ Entenderemos el concepto de desamortización de bienes de manos muertas como un procedimiento jurídico-político instaurado por la monarquía española y retomado en la república, encaminado a poner en el mercado de la oferta y la demanda los bienes amortizados por la Iglesia, con el fin de modernizar la estructura de la propiedad y pagar la deuda pública del Estado. En esta categoría se incluyen los bienes propios de la Iglesia o bienes eclesiásticos y los bienes civiles afectos a esta. En el caso de los bienes civiles, se contaban los censos (estos se hacían sobre bienes raíces, tales como casas, solares, lotes y fincas, entre otros, así como sobre semovientes), las capellanías, las cofradías de cualquier clase, las obras pías y las hermandades. Paralelamente a la desamortización se dieron otros procesos de liberalización de tierras, como el de repartición y distribución de baldíos y la enajenación o expropiación de tierras indígenas, los cuales no deben confundirse con la desamortización.

${ }^{2}$ Esta discusión se hizo evidente por parte de los fisiócratas, o teóricos de Carlos III, los cuales propugnaban una política limitadora de la adquisición de bienes por parte de la Iglesia. Sobre el asunto, véanse "Instrucción", en Moñino, Obras, 1867, p. 214; Jovellanos, Obras, 1845, y Campomanes, Tratado, 1765.

${ }^{3}$ La reacción de la Iglesia y de sus defensores no se hizo esperar. Los periódicos fueron el medio más expedito para criticar al gobierno y las leyes que vulneraban, según ellos, los derechos adquiridos por la Iglesia desde tiempo atrás. Véanse, entre otros, Exposición, 1853; Monitor, 1861; Opúsculo, 1854; Manifestación, 1863, y Grande, 1850.

${ }^{4}$ Uno de los puntos de acuerdo importante entre liberales y conservadores fue la eliminación del censo eclesiástico, que afectaba un alto porcentaje de las propiedades urbanas y rurales.

${ }^{5}$ La reforma fue ejecutada por Tomás Cipriano de Mosquera, Manuel Murillo Toro, Santos Acosta, Santos Gutiérrez y Santiago Pérez, todos ellos miembros del Partido Liberal. 
rica Latina- ${ }^{6}{ }^{6}$ también se observa escasez de estudios sobre el tema. En la región, México es el país que más avances ha presentado al respecto. La obra clásica de Jan Bazant sobre los bienes de la Iglesia en México y la revolución liberal, ${ }^{7}$ monografía que abarca la nacionalización y la venta de los bienes eclesiásticos mexicanos desde 1856 hasta 1875, centra su análisis en el Distrito Federal y en los estados de Puebla, Veracruz, San Luis Potosí, Michoacán y Jalisco. Según Bazant, la nacionalización de las propiedades eclesiásticas que quizá tuvo mayor influencia en la historia de México fue la decretada el 2 de noviembre de 1789 en Francia. Este estudio es importante, ya que ubica la desamortización como una coyuntura del proceso europeo. Rosa María Martínez de Codes observa que se ha dado mayor relevancia al proceso transformador del siglo XIX, mientras no se le da suficiente importancia al ordenamiento anterior. Asimismo, establece la importancia del marco jurídico como elemento esencial en un proceso más amplio, como lo es el de la transformación del régimen de la propiedad. ${ }^{8}$

Entre los estudios comparados, podemos señalar el de Robert J. Knowlton, ${ }^{9}$ cuya idea central gira alrededor de la pregunta de si la experiencia liberal mexicana influyó en los liberales colombianos en relación con las medidas anticlericales, específicamente en cuanto a la expropiación de sus bienes. Con este objeto, estudia tres aspectos fundamentales: las leyes desamortizadoras, las respuestas del clero a tales leyes y los resultados o efectos de estas. ${ }^{10}$ En la misma línea, José David Cortés ${ }^{11}$ plantea la hipótesis de que en México y Colombia las medidas que afectaron a la Iglesia católica formaban parte de un proyecto liberal mucho más amplio que implicaba romper con las antiguas estructuras coloniales, las cuales podían competir con el proyecto del Estado liberal.

En Colombia encontramos estudios como La Iglesia y el Estado en Colombia, ${ }^{12}$ que se constituye en el primero sobre el tema y cuyo objetivo principal consiste en justificar, a través de una serie de leyes, las propiedades de la Iglesia, así como denunciar la violación de sus derechos por parte del Estado. Otro estudio en la misma línea es Historia eclesiástica y civil de la

${ }^{6}$ Dada la importancia del tema, la Asociación de Historiadores Latinoamericanistas Europeos (AHILA) organizó grupos de trabajo alrededor del tema con el fin de establecer, entre otros, el estado actual de la investigación y propiciar estudios comparativos. Véase Prien y Martínez de Codes, Proceso, 1999.

${ }^{7}$ Bazant, Bienes, 1971.

${ }^{8}$ Martínez de Codes, "Luces”, 1999, pp. 33-60.

${ }^{9}$ Knowlton, "Expropriation", 1969, pp. 387-401.

${ }^{10}$ Ibid., p. 388.

${ }^{11}$ Cortés, "Desafuero", 2004, pp. 95-96.

${ }^{12}$ Restrepo, Iglesia, 1987, t. I. Para consultar otros estudios sobre el conflicto entre el Estado y la Iglesia en el siglo XIX, véanse González, Poderes, 1977, e "Iglesia”, 1987, pp. 91-163, y Villegas, Enfrentamientos, 1977. 
Nueva Granada. ${ }^{13}$ Este gira alrededor de una serie de argumentos en defensa de los bienes de la Iglesia y su derecho de posesión, para lo cual hace un recuento histórico de las diferentes reales cédulas y bulas que permitían a la Iglesia concentrar riquezas.

La investigación pionera de Fernando Díaz, ${ }^{14}$ publicada en 1977, sustenta que fue el general Mosquera el artífice no sólo de la desamortización de los bienes eclesiásticos, sino también de muchas de las reformas que se implementaron a partir de 1848. En el mismo estudio se presenta la desamortización como un proceso que se inicia en la segunda mitad del siglo XIX (es decir, a partir de 1850) y los bienes desamortizados de los monasterios menores de Pasto como uno de sus antecedentes inmediatos. En este estudio se analiza cuánto se desamortizó a la Iglesia en el Estado de Boyacá. Sobre el mismo tema, el autor escribió "Estado, Iglesia y desamortización", ${ }^{15}$ investigación cuyo hilo conductor es mostrar la participación de la Iglesia a partir de la colonia, atravesando el periodo de la independencia y la primera república.

Por su parte, Roberto Luis Jaramillo y Adolfo Meisel ${ }^{16}$ proponen un modelo interpretativo del proceso en el que primero separan las características de los bienes desamortizados (muebles, inmuebles, semovientes y censos), luego se preguntan si esta reforma fue un buen negocio y, por último, indagan sobre la relación costo-beneficio ${ }^{17}$ para la nación. En relación con el Estado Soberano de Bolívar y Cartagena, trabajan con cifras globales y señalan la necesidad de realizar investigaciones regionales que permitan entender la magnitud de este proceso. Avanzando hacia las investigaciones regionales, Adolfo Meisel e Irene Salazar ${ }^{18}$ plantean como idea central estudiar el proceso de desamortización para los estados federales de la Costa Caribe colombiana (Magdalena y Bolívar ${ }^{19}$ ) como un aporte a la historiografía económica colombiana. No obstante las muchas imprecisiones históricas, la importancia del estudio radica en que con este

${ }^{13}$ Groot, Historia, 1869-1870.

${ }^{14}$ Díaz, Desamortización, 1977, p. 6.

${ }^{15}$ Díaz, "Estado", 1989, pp. 197-222.

${ }^{16}$ Jaramillo y Meisel, "Más", 2010.

${ }^{17}$ Con este trabajo se trasciende del discurso político o social sobre el impacto de la desamortización en el caso colombiano y se comienza a cuantificar dicho proceso.

${ }^{18}$ Meisel y Salazar, "Desamortización”, 2012.

${ }^{19}$ Los autores plantean que "lo que fue la desamortización en el Caribe colombiano, que en esa época estaba compuesto por los Estados federales de Magdalena y Bolívar" en ibid., p. 120. Esta es una imprecisión histórica, ya que si se quiere hacer referencia a la región del Caribe colombiano, se debe incluir a Panamá. Este se encuentra en el Caribe y, lo más importante, era uno de los nueve estados soberanos de los Estados Unidos de Colombia. Debido a que Panamá fue uno de los Estados más diligentes para ejecutar la desamortización, su estudio se hace estrictamente necesario, pues su exclusión alteraría los resultados de este tipo de investigaciones. 
se da apertura al análisis cuantitativo regional de la desamortización de bienes de manos muertas.

Se han planteado varios argumentos tendentes a mostrar que la desamortización de bienes de manos muertas en lo que hoy es Colombia fue un proceso jurídico-político instaurado por la monarquía española en la segunda mitad del siglo XVIII, en la coyuntura del liberalismo económico, y que este proceso pervivió hasta $1887 .^{20}$ En una tesis doctoral sobre la liberalización de tierras en Colombia se retomó el tema para analizar el proceso global en Colombia a partir del análisis cuantitativo de los aportes de cada uno de los nueve estados soberanos ${ }^{21}$ que conformaban los Estados Unidos de Colombia; también se propone que esta política de carácter nacional fue posible a partir de la articulación con las regiones.

Faltan más investigaciones que consideren la desamortización en los Estados Soberanos de la costa Caribe, por lo pronto en este artículo se analizará la articulación de las políticas desamortizadoras del Estado Soberano de Bolívar con la Junta Suprema del Crédito Nacional ${ }^{22}$ (Agencia General de Bienes Desamortizados), a partir de un esfuerzo de cuantificación parcial que permita tener una idea global de la forma como se reestructuró la propiedad en los ámbitos urbano y rural.

Para sustentar lo anterior, el artículo está organizado en cuatro partes. La primera trata de la organización administrativa para la desamortización de bienes de manos muertas en el Estado Soberano de Bolívar y su articulación con la Agencia General de Bienes Desamortizados. La segunda parte se centra en el análisis cuantitativo-comparativo de la desamortización en los Estados Unidos de Colombia ${ }^{23}$ y en el Estado Soberano de Bolívar. ${ }^{24}$ En la tercera y cuarta partes se analiza a los censualistas, ${ }^{25}$ así como sus

${ }^{20}$ Cruz, Proceso, 2009, pp. 203-222.

${ }^{21}$ Cruz, "Proceso", 2012.

${ }^{22}$ Decreto, 1864, p. 1.

${ }^{23} \mathrm{El}$ actual territorio colombiano, de acuerdo con los marcos constitucionales, las formas de gobierno y los conflictos entre los partidos políticos en el siglo XIX, recibió varios nombres: República de Colombia (1821-1832), Estado de la Nueva Granada (1832-1843), República de la Nueva Granada (1843-1858), Confederación Granadina (1858-1863), Estados Unidos de Colombia (1863-1886). La última Constitución del siglo XIX fue la de 1886, que, después de múltiples actos legislativos que la modificaron, fue derogada en 1991. En la actual Constitución, promulgada en 1991, aún se conserva el nombre de República de Colombia.

${ }^{24}$ La implantación de la federación como forma de gobierno se dio luego de muchos conflictos, de los que a partir de 1855 salió victorioso el partido liberal. Lo que hizo posible la instauración de la denominada Primera República Liberal. La Constitución de 1863 o de los Estados Unidos de Colombia tenía como fundamento la soberanía de los estados miembros de la federación, producto de la cual se constituyeron nueve estados soberanos: Bolívar, Cauca, Cundinamarca, Boyacá, Antioquia, Panamá, Santander, Magdalena y Tolima.

${ }^{25}$ Se refiere a los que prestaban dinero y daban como garantía una propiedad, tales como fincas, haciendas, bienes muebles, semovientes u otras. Estas hipotecas se hacían generalmente a favor de la Iglesia o de alguna de sus instituciones. 
deudas y remates de bienes urbanos, para clasificar a los propietarios por grupos, de acuerdo con el tamaño del censo ${ }^{26}$ y los bienes amortizados. ${ }^{27}$

\section{ORGANIZACIÓN ADMINISTRATIVA PARA LA DESAMORTIZACIÓN DE BIENES DE MANOS MUERTAS EN EL Estado SOBERANO de Bolívar ${ }^{28}$}

La rebelión de las provincias colombianas contra el gobierno central, y su lucha por el federalismo, hicieron posible la reforma de la propiedad. Sin embargo, esta no tuvo ningún viso de tipo social, en el sentido de procurar una distribución igualitaria de tierras y bienes, sino que fue un movimiento encaminado a establecer las políticas económicas liberales, a sortear el déficit estatal y a reducir la endémica deuda pública externa e interna, que se habían convertido en un cuello de botella para el Estado central.

Los bienes captados se remataron entre los particulares que contaban con poder adquisitivo bajo las siguientes condiciones: a) que tuvieran títulos de la deuda pública; $b$ ) que contaran con dinero en efectivo -condición necesaria para realizar la transacción-, y c) que tuvieran propiedades a censo -a los censualistas se les ofrecieron garantías que les permitieran retener sus propiedades.

Para hacer posible esta reforma fue necesario dictar una nueva Constitución y adecuar el marco jurídico a las nuevas necesidades. Se apro-

\footnotetext{
${ }^{26}$ Se constituía el censo cuando se sujetaban algunos bienes inmuebles al pago de un canon o rédito anual en retribución de un capital que se recibía en dinero, o del dominio pleno o menos pleno que se transmite de los mismos bienes. Según Restrepo, en Colombia la mayoría de los censos eran consignativos; conforme a esta figura, un individuo daba a otro cierta suma y este se comprometía, en contraprestación, a pagarle un rédito anual (generalmente $5 \%$ ) y le garantizaba la obligación con una hipoteca suficiente. Por lo común, la duración del censo era indefinida. También existía, aunque muy poco usado, el censo reservativo. Este consistía en que si un individuo tenía una finca que quería enajenar para proporcionarse una renta, la vendía a otro, por cierta suma, estipulando que dicha suma, en lugar de pagarla, la reconocería a censo y la aseguraría en la misma o en otras fincas. En esta modalidad de censo se transfería el pleno dominio del inmueble. Otro tipo de censo existente era el enfitéutico, en virtud del cual una persona cedía a otra el dominio útil de una finca, reservándose el derecho de percibir del enfiteuta una pensión anual en reconocimiento de este mismo dominio. En el caso estudiado, no se halló este tipo de censo.

${ }^{27}$ Los bienes amortizados eran de dos clases: los civiles y los eclesiásticos. La amortización civil se entendía como la separación de la circulación o libre comercio a favor de algunas instituciones tales como fideicomisos, mayorazgos, patronatos y memorias. A su vez, la amortización eclesiástica se definía como las adquisiciones hechas directamente por la Iglesia.

${ }^{28}$ El Estado Soberano de Bolívar, según el censo de 1876, contaba con una superficie de $70000 \mathrm{~km}^{2}$, de los cuales $30000 \mathrm{~km}^{2}$ estaban habitados por 241704 habitantes, distribuidos en diez provincias, incluyendo las tierras cultivables, y $40000 \mathrm{~km}^{2}$ en tierras baldías y deshabitadas. Es decir, en relación con el total de la superficie, se calcula una densidad de población de $3.4 \mathrm{hab} . / \mathrm{km}^{2}$. La provincia de Cartagena, por su parte, contaba con 15590 habitantes, distribuidos en $115 \mathrm{~km}^{2}$ (es decir, 135.5 hab./km²). Véanse Estadística, 1876, pp. 31-35, y Pérez, Geografía, 1883.
} 
MAPA 1. COLOMBIA, 1843-1886

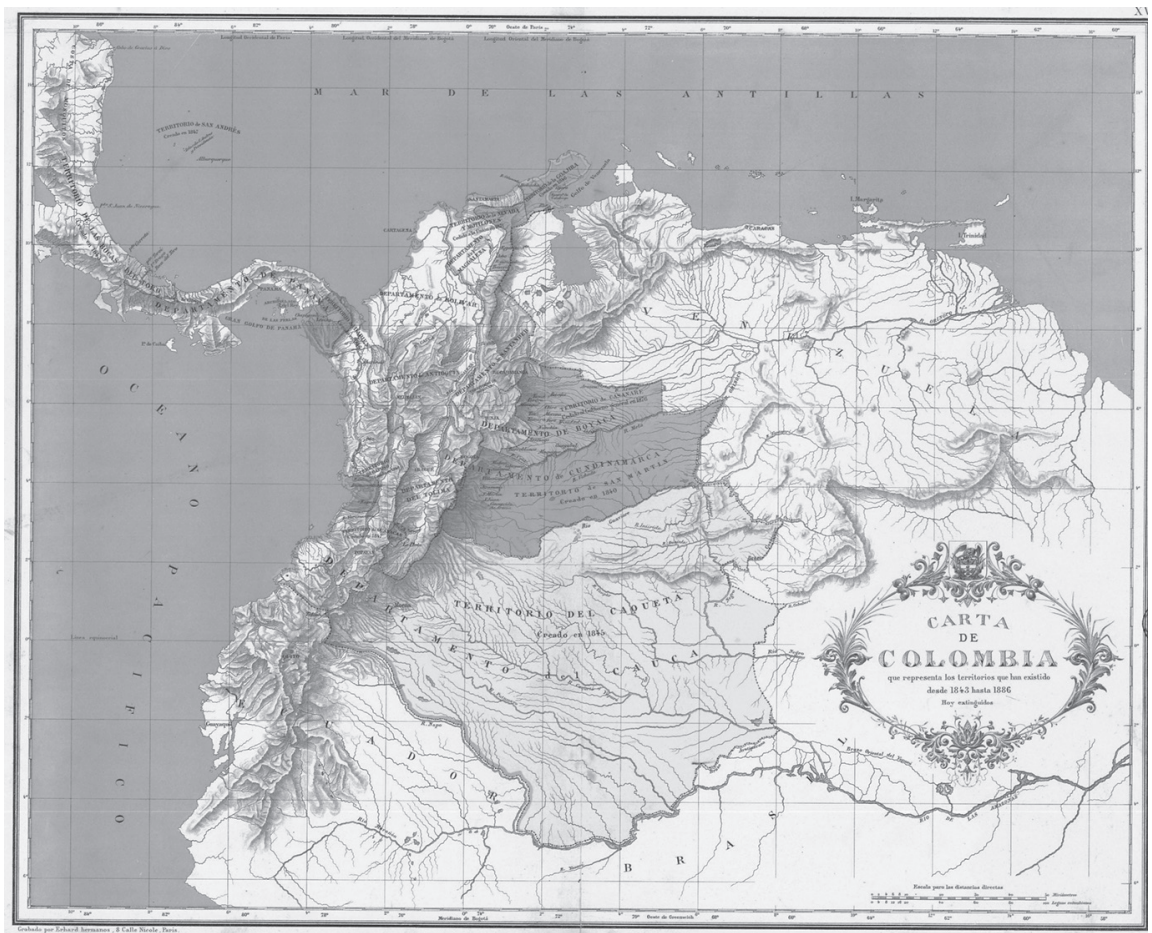

Fuente: Carta de Colombia que representa los territorios que han existido desde 1843 hasta 1886, hoy extinguidos. Carta XV en Codazzi, Paz y Pérez, Atlas, 1889.

baron las normas referentes a la desamortización de bienes de manos muertas a partir de 1861, las cuales fueron de obligatorio cumplimiento en cada uno de los estados soberanos. Dentro del paquete de reformas también se adoptó la federación como alternativa político-territorial ${ }^{29}$ que reconoció la autonomía regional, representada en los Estados y regulada por el Congreso de la Unión.

No obstante la autonomía de que gozaban los Estados Soberanos, ciertas políticas eran del resorte de los Estados Unidos de Colombia, en

${ }^{29}$ Para un análisis político-jurídico riguroso de los estados federados, véase Restrepo, "Constituciones", 1985. 
cuyo gobierno estaban representados cada uno a través de sus parlamentarios. La desamortización fue una medida de carácter nacional, cuyo dinamismo y resultados dependieron básicamente de la apropiación que hizo de ella cada Estado.

Para lograr estos resultados, se creó la Agencia General de Bienes Desamortizados, estructurada en diez juntas dentro de las que se contaba una Junta Superior de Bienes Desamortizados y nueve juntas subalternas, ubicadas en cada uno de los estados soberanos. Cada junta subalterna, a su vez, estaba dividida en distritos o círculos, acordes con su división administrativa territorial. Todas ellas dependían de la Junta Superior inserta en el Ramo de Bienes Desamortizados, como cuenta especial de la Hacienda nacional.

El Estado Soberano de Bolívar estructuró cinco oficinas de agrimensores con el fin de que hubiera claridad entre los linderos de las propiedades del Estado y los particulares. Las oficinas fueron establecidas en las provincias de Barranquilla, Sabanalarga, Cartagena, El Carmen, Mompox, Corozal, Chinú, Sincelejo, Magangué y Lorica. ${ }^{30}$ A partir de 1866 -uno de los años más importantes en cuanto a remates de bienes-, la Junta estaba organizada de acuerdo con la estructura según el cuadro 1 .

En 1875, cuando se hizo evidente la decadencia de la reforma, ${ }^{31}$ la administración de los bienes desamortizados seguía organizada en círculos, pero con algunas modificaciones. Así, los círculos $1^{\circ}$ y $2^{\circ}$ de la ciudad de Cartagena, y el círculo $3^{\circ}$ de Sincelejo, Chinú, Majagual y Corozal, se denominaban Agencia Subalterna de Bienes Desamortizados; es decir, estos se hallaban jerárquicamente en el mismo nivel, cada uno con su respectivo agente responsable. Del círculo de Cartagena estaba encargado Senén González, y del círculo $3^{\circ}$ de Sincelejo, Francisco Iriarte -este círculo comprendía solamente a Tolú, donde el agente tenía su residencia. Del círculo de Chinú estaba encargado Lizardo Delgado, mientras que el de Majagual estaba a cargo de Tomás Verjel Róyers y el de Corozal de Leandro Mogollón. Mompox y Magangué, que incluía a Yatí y San Sebastián de Madrid, eran una Administración Subalterna de la Hacienda Nacional, y estaban a cargo de Manuel E. Rojas y Ventura García.

Si comparamos ambas administraciones, encontramos que en la de 1866 existía un agente principal y agentes subalternos por cada círculo, mientras que en la de 1875 desaparece el agente principal, se simplifica un poco más la estructura y los círculos de Mompox y Magangué, por su importancia para el gobierno de la Unión, se elevan a la categoría de

\footnotetext{
${ }^{30}$ Gaceta de Bolívar, 30 de enero de 1870, núm. 671.

${ }^{31}$ Cruz, "Proceso", 2012, pp. 159-160.
} 


\section{CUADRO 1. AGENTES ENCARGADOS DEL RAMO \\ DE BIENES DESAMORTIZADOS EN EL ESTADO SOBERANO DE BOLÍVAR HASTA 1866}

\begin{tabular}{lll}
\hline Agente principal & \multicolumn{1}{c}{ Agentes subalternos } & \multicolumn{1}{c}{ Círculos } \\
& & \\
& Ezequiel de la Espriella & $1^{\circ}$ de Cartagena \\
& Miguel J. de la Hoz & Santo Tomás \\
& Rodrigo Pantoja & Barranquilla \\
& Salvador Matos & Mompox \\
& Francisco Pareja & Magangué, Yatí y San Sebastián \\
& Miguel Vidales & Majagual, Achí y Boyacá \\
Gabriel Tatis & Leonardo Mogollón & Corozal \\
& Manuel de la Espriella & Arjona \\
& Manuel de la Cruz Flórez & Sincé \\
& Facundo Madrid & Del $1^{\circ}$ de Sincelejo \\
& Manuel P. de la Cerra & Del $2^{\circ}$ de Sincelejo \\
& Francisco Iriarte & Del $3^{\circ}$ de Sincelejo \\
& Manuel D. Mendoza & Del de Chinú \\
\hline
\end{tabular}

Fuente: Informe, 1867.

Administración Subalterna de la Hacienda Nacional, lo que implicó que dejaran de depender de Cartagena. Estas modificaciones se debían, en primer lugar, a las reformas del ramo que se fueron haciendo sobre la marcha con el fin de que fuera más eficiente $y$, en segundo término, a la presión que ejercían algunas municipalidades.

\section{ANÁLISIS CUANTITATIVO-COMPARATIVO DE LA DESAMORTIZACIÓN EN LOS Estados Unidos de Colombia y en el Estado Soberano de Bolívar}

Según lo dicho y teniendo en cuenta la amortización civil, encontramos que los bienes se agrupaban en tres categorías: a) los bienes raíces, entre los que se contaban casas, fincas, haciendas, hatos, hatillos y solares, entre otros; $b$ ) los censos y deudas, es decir, todos aquellos bienes que estaban censados a favor de la Iglesia, y $c$ ) los semovientes, que comprendían el ganado mayor y el menor. Si lo analizamos desde el punto de vista de la estructura de la Hacienda Nacional, encontramos que se clasificaban en bienes eclesiásticos (es decir, aquellos afectos a la Iglesia o que le pertenecían directamente), los bienes de educación y beneficencia y bienes de las 
municipalidades. ${ }^{32} \mathrm{Al}$ iniciarse la expropiación de los bienes de la Iglesia, entre septiembre de 1861 y finales de 1864, la Unión había captado por desamortización en estas tres categorías la suma de 6351166.22 pesos. $^{33}$ Durante el periodo señalado el Estado de Bolívar inscribió en la categoría de bienes eclesiásticos $9 \%$ en bienes urbanos y $11.1 \%$ en censos, mientras que en bienes de beneficencia y educación inscribió, por urbanos, $72 \%, \mathrm{y}$ por censos, $20 \%{ }^{34}$ del total de los bienes por este concepto. Es decir, en ese renglón el Estado de Bolívar fue el que más expropió bienes. La expropiación de bienes urbanos de las municipalidades representó 19\% del total de los inscritos. Sumando los tres conceptos, es decir, bienes eclesiásticos, bienes de educación y beneficencia, y bienes de municipalidades, el Estado de Bolívar participó con 8\% de inscritos en el total nacional.

Dentro del Estado y en los mismos años referidos, encontramos que el Círculo Administrativo de Cartagena fue el más diligente en la inscripción de bienes ${ }^{35}$ raíces, censos y deudas, de tal manera que en esta ciudad la reforma fue más eficiente, por tanto, la propiedad se trasformó en un mayor grado. Así, porcentualmente Cartagena inscribió 91.97\% del total de los bienes, mientras en los ocho círculos restantes se registraron los siguientes porcentajes de inscripción: Chinú, 2.75\%; Magangué, 1.82\%; Lorica, 1.22\%; Corozal, 0.69\%; Mompox, 0.64\%; Nieto, 0.06\%; Mahates, 0.00\%; Barranquilla, 0.01\%, y Sabanalarga, cero por ciento.

Sin embargo, en el informe enviado por el agente principal de bienes de manos muertas en $1864^{36}$ no había sido posible depurar la información debido al movimiento revolucionario que tuvo lugar en el Estado de Bolívar ${ }^{37}$ en casi todas sus provincias, lo cual impidió que los agentes

\footnotetext{
${ }^{32}$ Se incluyeron las municipalidades debido a que se consideraba que las rentas de los comunes o municipios habían perdido capitales considerables, en concursos y quiebras, por haber dado en venta a censo las propiedades inmuebles, tal como se lee en el artículo 2 del decreto de 9 de septiembre de 1861. Véase Recopilación, 1862, miscelánea 1266, pieza 7. Por otra parte, desde la segunda mitad del siglo XVIII se consideraba que las tierras en poder de la Iglesia, los municipios y otros tipos de manos muertas rendían poco, quedando al margen del libre comercio y, por el carácter privado de sus propietarios, no tributaban a favor de la Hacienda. Véase esta discusión en Jovellanos, Obras, 1845, pp. 23-56.

${ }^{33}$ Desagregados de la siguiente manera: en bienes eclesiásticos, 4768474.26 pesos; en educación y beneficencia, 951135.91 pesos, y en bienes de las municipalidades en manos muertas, 6982722.27 pesos.

${ }^{34}$ Ibid.

${ }^{35}$ La celeridad en la inscripción y remates de bienes dependía, en gran parte, del agente principal de bienes desamortizados, el cual recibía un porcentaje sobre dichos bienes.

${ }^{36}$ Informe, 1865, pp. 16 y ss.

${ }^{37}$ El malestar generado por el exceso de centralismo y la pérdida de la autonomía había desatado mucha inconformidad en las provincias. De esta manera, a partir de 1855 se adoptó la federación a través de la creación de los estados federados. En este contexto, en Cartagena se inició un movimiento político y social tendente a deslegitimar al gobierno conservador, al cual consideraban arbitrario y violatorio de los derechos individuales, plasmados en la Constitución de 1858.
} 
subalternos o especiales pudieran reportar todos los bienes inscritos de cada una de las provincias. En cuanto a los remates, tenemos que hasta diciembre de 1864 se habían rematado, por fincas raíces, 34988.80 pesos; por muebles y semovientes no hubo remates; por avalúo se recibió la suma de 14500 pesos; por remates se percibieron 31808 pesos, y por derechos de título, 0.0. Estas cantidades corresponden a $2 \%$ del total nacional (véase cuadro 2).

No obstante, cuando se llevó a cabo la desamortización muchos bienes raíces, muebles y censos enajenados redimidos o cedidos no habían entrado al activo del ramo. Entre estos tenemos el edificio del extinguido convento de Santa Clara, cedido al Estado por decreto de 11 de junio de 1864 por 50000 pesos. $^{38}$

Debido al movimiento revolucionario se generaron gastos de guerra, que se sufragaron con algunos fondos de desamortización de algunas provincias, así a) de la provincia de Lorica se tomaron 9496.80 pesos, de los cuales 9064.80 correspondían al rubro de censos y deudas y 432 a semovientes; $b$ ) de la provincia de Magangué se dispuso de 3638.74 pesos para gastos de guerra, de los cuales 64 correspondían a bienes raíces y 661.74 de la cuenta de censos y deudas; $c$ ) de las provincias de Sincelejo y Corozal se gastaron 4398.50 pesos, de los cuales 656 correspondían a censos y deudas y 624 a semovientes, y $d$ ) de la provincia de Chinú se tomaron 1428 pesos, representados en bienes raíces (80 pesos), censos y deudas (1 056 pesos) y semovientes (292 pesos). ${ }^{39}$ En total, se gastaron en la guerra 71227.64 pesos ${ }^{40}$ recursos sustraídos del ramo de bienes desamortizados y que el general Juan José Nieto no reportó en su informe sobre la guerra que "regeneró" al Estado de Bolívar, ${ }^{41}$ pues según este los pocos recursos con los que contaban venían de los aportes personales de algunos de los miembros que lideraban el movimiento.

En cuanto a los bienes correspondientes al año de 1866, tenemos que en total se inscribieron por el Estado 655091.75 pesos, de los que deben descontarse, según el agente, 135202.10 pesos por avalúos; 75513 pesos por remates, y 174821.50 pesos por derechos de títulos y aprovechamientos. Esto significa que quedó disponible en el ramo, por concepto de desamortización, la suma de 130855 pesos por bienes raíces y semovientes y 650 pesos en muebles y semovientes -monto contado luego de los remates $\mathrm{y}$ descuentos por gastos de guerra.

\footnotetext{
${ }^{38}$ Informe, 1865 , pp. 16 y ss.

${ }^{39}$ Ibid.

${ }^{40}$ Ibid.

${ }^{41}$ Nieto, Bosquejo, 1862.
} 


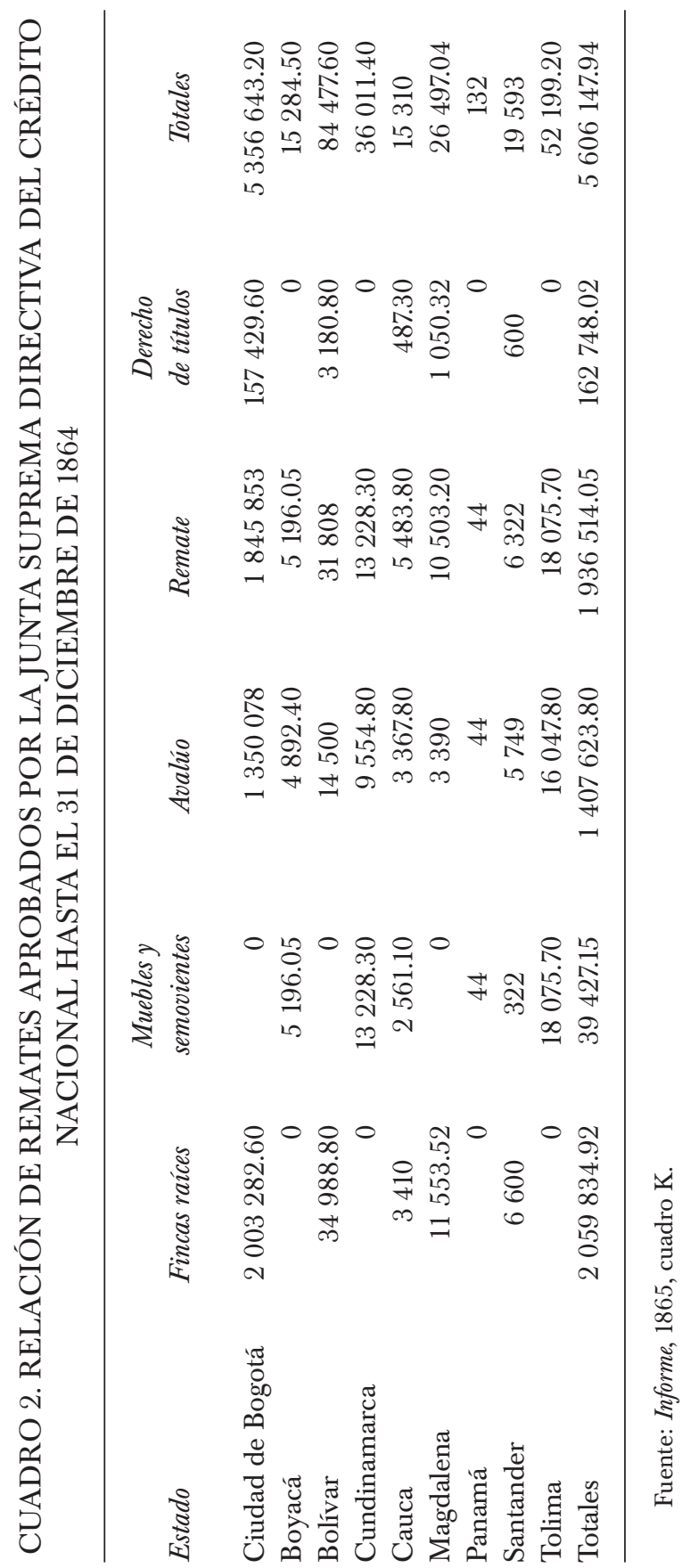


Los bienes inscritos por concepto de fincas raíces, censos, deudas, muebles y semovientes por el Estado representaron 6\% de acuerdo con el consolidado nacional (véase gráfica 1), porcentaje compartido con Cundinamarca y Panamá. Este valor restante queda en el aire de acuerdo con los datos suministrados; es decir, no se refleja a través de ningún concepto, por lo que al Estado de Bolívar, según el balance de 1866, solamente le quedaban en el ramo por bienes desamortizados 126385 pesos. Esto puede deberse a muchas causas, tales como la poca capacitación que tenían los agentes principales y subalternos ubicados en las provincias o la corrupción administrativa que permeó este proceso permanentemente.

Los ingresos del Estado por venta en ese mismo año fueron de 174821.50 pesos; esta cifra incluye los derechos de título y aprovechamientos, y corresponde a $1 \%$ del total recaudado (véase cuadro 3).

En 1866 la inscripción de bienes tuvo un comportamiento promedio, mientras las ventas de dichos bienes tendió a la baja, pues se captó por ingresos 21\% del total disponible (es decir, 79\% de los bienes quedaron por rematarse). Al intentar buscar una explicación sobre esta situación, en primer lugar debemos apreciar que las guerras internas condujeron a que las rentas se diezmaran. Por otra parte, en el territorio en general la gente no se animaba a comprar bienes desamortizados, agregándole además que según los informes de los agentes superiores, en las provincias no existían suficientes personas con poder adquisitivo -representado ya en liquidez, ya en bonos de la deuda nacional- con capacidad de comprar y circular rápidamente los bienes desamortizados. Otro de los posibles factores determinantes radica en que las elites de poder del Estado tenían muchos de sus bienes a censo redimible a 5\%, como lo veremos más adelante; esto implicaba que no contaban con los recursos para comprar otros bienes, ni tampoco para liberar sus propios censos.

En 1868, el Estado Soberano de Bolívar inscribió, entre bienes raíces, muebles y semovientes, la suma de 783954.25 pesos, ${ }^{42}$ de los cuales se remataron 174821.50 pesos; del total de estos bienes, el Estado invirtió en usos públicos y guerra la suma de 97678.30 pesos. Al terminar el año fiscal tenía en existencia la suma de 126385.10 pesos; en relación con las anteriores cifras, se observa que al cerrar el año 1868, de acuerdo con lo aportado al consolidado nacional y estimando las variables de bienes inscritos, vendidos y utilizados para gastos de usos públicos y guerra, se tenía la siguiente relación: bienes inscritos, $66 \%$; ventas efectivas, $15 \%$; gastos de guerra y usos públicos, $8 \%$, y existencias, $11 \%$, según sus propias cuentas. ${ }^{43}$

\footnotetext{
${ }^{42}$ Sin incluir descuentos posteriores.

${ }^{43}$ Por otra parte, el Estado de Bolívar falló en el envío de las cuentas en 1867 y parte de 1868.
} 
GRAFICA 1. INSCRIPCIÓN DE BIENES DE MANOS MUERTAS, 1866

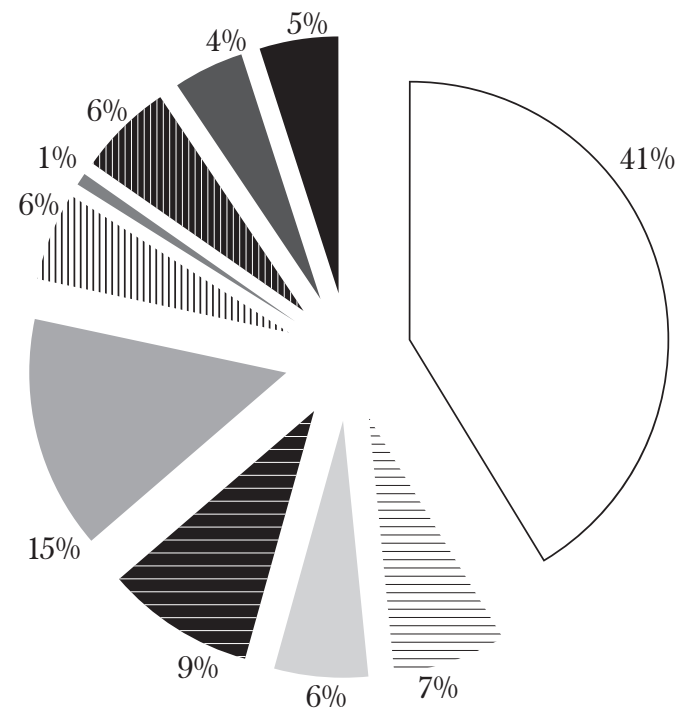

$\square$ Ciudad de Bogotá

$\equiv$ Estado de Antioquia

Estado de Bolívar

E Estado de Boyacá

Estado de Cauca

| I Estado de Cundinamarca

- Estado de Magdalena

nu Estado de Panamá

Estado de Santander

Estado de Tolima

Fuente: Informe, 1867.

CUADRO 3. CONSOLIDADO NACIONAL DE INGRESOS POR VENTAS DE BIENES DESAMORTIZADOS, $1866^{\mathrm{a}}$

Estado

Ciudad de Bogotá

Estado de Antioquia

Estado de Bolívar

Estado de Boyacá

Estado de Cauca

Estado de Cundinamarca

Estado de Magdalena

Estado de Panamá

Estado de Santander

Estado de Tolima

Totales
Ingresos por ventas

5150645.20

238511

174821.50

441473.55

518664.55

463886

17913.45

136626.30

382778.30

64949.65

7590269.50

a Informe, 1867.

Fuente: Cruz, "Proceso", 2012, cuadro 20. 
Comparando la participación del Estado en relación con el total nacional, tenemos que, en bienes inscritos, aportó $6.51 \%$; en ventas efectivas, 1.74\%; en usos públicos y guerra, $12.34 \%$, y en existencia de bienes, $8.21 \%$. Al comparar el porcentaje del Estado de los bienes inscritos y ventas reales, encontramos que la inversión en gastos públicos y de guerra fue alta. Incluso se gastó más de lo que se remató en ese año.

Entre los años 1870-1875 se captaron 43826 pesos por concepto de avalúos; 64466 en remates, y 2504.13 en réditos y arrendamientos de título (véase cuadro 4).

En general, el Estado Soberano de Bolívar aportó al ramo de bienes desamortizados la suma de 1183885.47 pesos en bienes inscritos; de estos, se remataron bienes por valor de 445917 pesos (es decir, 37\% de lo inscrito). Ahora bien, si se parte de que el total nacional de bienes inscritos fue de 30776686.40 pesos $^{44}$ y los remates de 24430016.61 pesos, se tiene que la participación en catorce años -contados desde 1861 hasta 1875- del Estado Soberano de Bolívar en el consolidado nacional fue, en bienes inscritos, de $4 \%$, y en ventas efectivas, $1.84 \%$ (véase cuadro 5).

De estas cifras puede deducirse que su participación fue baja, lo que permite plantear que la circulación de bienes no fue tan efectiva como se esperaba, es decir, no se hizo evidente en los remates y las ventas. Por otra parte, también se observa que la mayoría de los remates se hizo sobre bienes urbanos, tanto en la capital de Bolívar como en la capital de las provincias; esto significa que, tal como ocurría en la tendencia nacional, la desamortización se llevó a cabo sobre los bienes ubicados en las ciudades capitales e intermedias. Esta situación se debía, según los agentes principales de bienes desamortizados, a las dificultades para hacer cumplir la norma y a la poca motivación que mostraban los agentes subalternos o especiales para ejecutar este proceso en zonas más alejadas. ${ }^{45}$

En 1868 se registraron más inscripciones por parte del Estado, mientras que el mayor número de remates se dio entre 1866 y 1868 (véase cuadro 6). Otro aspecto de la desamortización es el relacionado con la complejidad administrativa, no en su estructura, sino en su funcionamiento, es decir, los balances entre bienes, censos y semovientes inscritos, así como en los remates, resultaban confusos debido a las demandas por inclusión de bienes en la categoría de desamortizados, aunque en realidad no lo eran. Esto condujo a que se abrieran otras cuentas sobre devolución de bienes, los cuales se descontaban de las existencias que venían acumuladas de años anteriores.

\footnotetext{
${ }^{44}$ Debido a las inconsistencias en los informes de los agentes de bienes desamortizados, se tomó la cifra más baja, tanto para los bienes inscritos como para los rematados.

${ }^{45}$ Véanse Informe, 1865, 1867, 1869, 1874 y 1875.
} 
CUADRO 4. RELACIÓN DE BIENES VALUADOS Y REMATADOS POR EL ESTADO SOBERANO DE BOLÍVAR ENTRE 1870 Y 1875

\begin{tabular}{lccc}
\hline & & & Réditos de arrendamientos \\
Años & Bienes valuados & Bienes rematados & y títulos \\
$1870-1871$ & 18750 & 33027 & 2504.13 \\
$1870-1871$ & 160 & 2200 & - \\
1873 & 8600 & 3160 & - \\
1874 & 1000 & 1206 & - \\
1875 & 15316 & 24873 & 2504.13 \\
Total & 43826 & 64466 & - \\
\hline
\end{tabular}

Fuentes: elaboración propia con base en Cruz, "Proceso", 2012, cuadros 33-43 y 47; Memoria, 1870, 1871, 1872 y 1873, e Informe, 1874, 1875 y 1876.

Por ejemplo, según la Agencia General de Bienes Desamortizados, en 1874, en el Estado Soberano de Bolívar, se valuaron en bienes 1000 pesos, que se remataron en 1206 pesos. Sin embargo, se observa que en la existencia del mismo año se ordena descontar 13686 pesos por devolución de bienes; esto indica que en las cuentas de los ingresos por años no se contaban las existencias, ni tampoco las devoluciones. Esta situación dio margen para que se acentuara la corrupción permanente en los asuntos de este ramo, que fue denunciada tanto por ciudadanos como por políticos, quienes señalaron que la desamortización había perjudicado a la república.

Denuncias como estas obligaron a Narciso González Lineros, quien dirigió la Agencia General por cuatro años, a publicar un opúsculo donde defendía su gestión -y la de los agentes principales que lo acompañaronfrente a las acusaciones de corrupción y malos manejos de este fondo. ${ }^{46}$ En todo caso, involucrados los agentes o no en episodios de corrupción, lo que sí es evidente es el desorden en las cuentas, así como los remates realizados por debajo del precio de avalúo. Esta situación condujo a que las deudas contraídas por el Estado con los censualistas y censatarios no se lograran pagar en el tiempo establecido. ${ }^{47}$

${ }^{46}$ González, Nueva, 1866.

${ }^{47}$ Para un análisis detallado sobre el tema de la desamortización de bienes de manos muertas en Colombia, véase Cruz, "Proceso", 2012. 


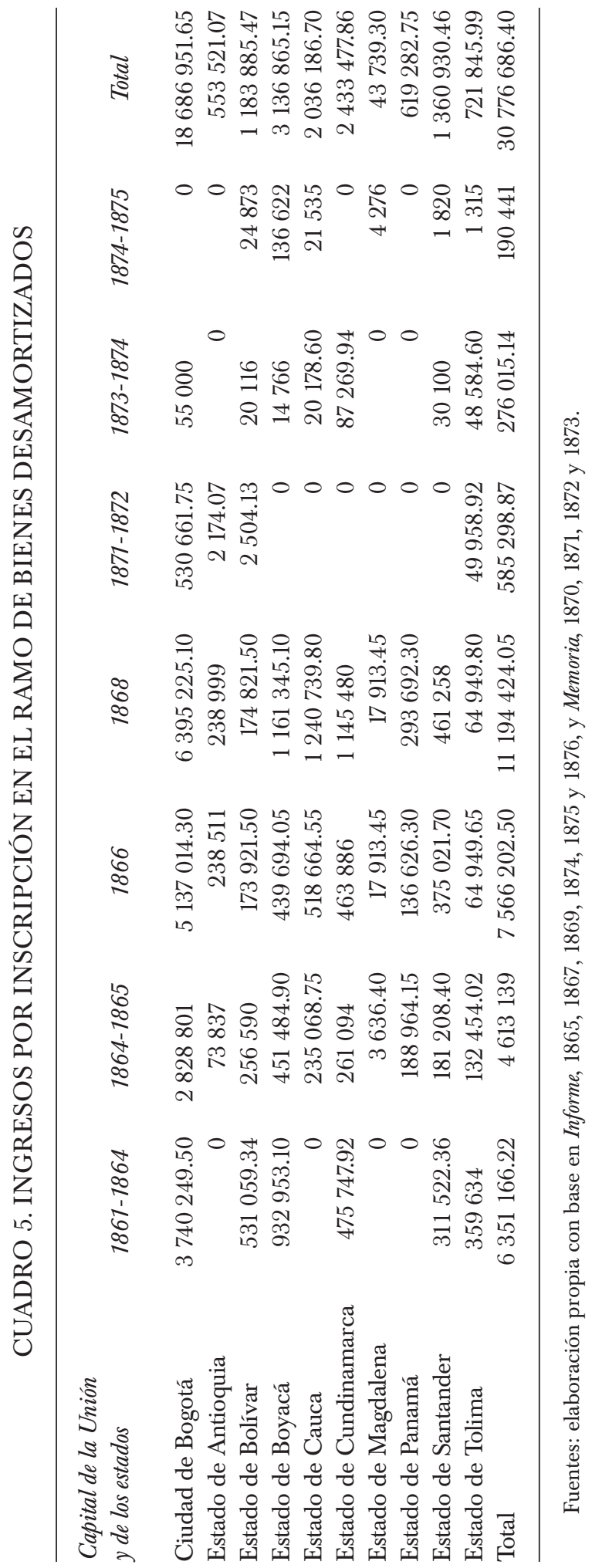


CUADRO 6. CONSOLIDADO DE BIENES DESAMORTIZADOS POR EL ESTADO SOBERANO DE BOLÍVAR, 1864-1875

\begin{tabular}{lccc}
\hline Años & Bienes valuados & Bienes rematados & $\begin{array}{c}\text { Réditos y } \\
\text { arrendamientos títulos }\end{array}$ \\
$1864-1865$ & 668354.45 & 31808 & 157429.60 \\
1866 & 655091.75 & 174821.50 & - \\
1868 & 783954.25 & 174821.50 & - \\
$1870-1871$ & 18750 & 33027 & - \\
$1870-1871$ & 160 & 2200 & - \\
1873 & 8600 & 3160 & - \\
1874 & 1000 & 1206 & - \\
1875 & 15316 & 24873 & 2504.13 \\
Total & 2151226.45 & 445917 & - \\
\hline
\end{tabular}

Fuente: elaboración propia con base en Cruz, "Proceso", 2012, cuadros 15-49.

\section{REDENCIÓN DE CENSOS. Estudio de CASOS}

En el proceso de liberalización de tierras se contemplaron los censos, debido a que sobre ellos recaían deudas con la Iglesia, la cual era la mayor censataria. Por tal razón, y como se expresó anteriormente, los censos se constituyeron en un obstáculo para los nuevos postulados económicos liberales, pues estos, como lo expresó Salvador Camacho Roldán, ${ }^{48}$ generalmente terminaban en ruinas porque no podían con la carga de los intereses que debían pagar. Por esta razón, el Estado de la Unión, en el marco de la captación de recursos y liberalización de bienes, determinó por la Ley del 30 de mayo de $1851^{49}$ iniciar su redención.

Para el caso que nos ocupa, tenemos que entre 1863 y 1868 -momento del auge de la desamortización- se redimieron al Estado censos por valor de 272523.82 pesos, ${ }^{50}$ es decir, $5.73 \%$ del total recaudado entre todos los Estados. Por ejemplo, Agustín Vélez ${ }^{51}$ tenía deudas por censo de 10908 pesos, que estaban respaldadas por cuatro casas en diferentes calles de la ciudad amurallada de Cartagena y una hacienda denominada San Antonio de Mamonal, en las inmediaciones de la bahía y en jurisdicción

\footnotetext{
${ }^{48}$ Camacho, Escritos, 1976, p. 56.

${ }^{49}$ Preston, Crédito, 1983, pp. 27-28.

${ }^{50}$ Informe, 1865, pp. 1-20.

${ }^{51}$ Ibid., pp. 1 y ss.
} 
de Turbaco. Los prestamistas fueron la capellanía de la señora Ventura Rangel, por 1000 pesos de capital de censo; la canonjía de la diócesis de Cartagena, 2216 pesos, y la capellanía de las Almas de los Indios de Turbaco, por 720 pesos. A su vez, la casa número 62 de la calle de las Carretas tenía préstamos por la suma de 2160 pesos a favor del colegio de Bolívar, capítulo Catedral, el monasterio de Santa Clara, el sacristán de la parroquia de Pasto y la Casa de Beneficencia. La hacienda de San Antonio de Mamonal tenía deudas de capital por 4812 pesos a favor del monasterio de Santa Teresa de Cartagena, el convento de San Francisco de Santa Marta, el colegio de Bolívar, las Ánimas de la Iglesia Catedral de la ciudad de Cartagena y una capellanía de Basilio del Toro Mendoza. De la situación financiera de Agustín Vélez se desprende, en primer lugar, que sus deudas trascendieron los límites del Estado de Bolívar; en segundo lugar, se deduce que no tenía una actividad productiva que le permitiera amortizar los censos adquiridos, y tercero, que la mayoría de los bienes de las personas estaban en manos muertas, los cuales terminaban pasando a la Iglesia como acreedora de los mismos.

Por su parte, José Germán Ribón, ${ }^{52}$ que era el censualista con mayor capital a censo con un total de 11280 pesos, lo tenía concentrado básicamente en dos núcleos de bienes: las casas 3 y 14, en la plaza principal de La Albarrada de Mompox, más tres casas y catorce tiendas en el Chiquillo de Mompox. El primer núcleo estaba a favor de la Casa Obra Pía de Cartagena, por 8080 pesos en capital, y 3200 pesos a favor de la capellanía del señor Rafael de Ercoreca. Esto sin incluir los intereses, que ascendían a 5\% anual; de estos sólo podemos calcular los correspondientes a 1864, que son los reportados al momento de la desamortización. De los demás años no se tiene referencia; es decir, no se sabe desde cuándo tenía sus bienes en manos muertas, de tal manera que en el año mencionado debía en intereses la suma de 56400 pesos.

A estos censualistas los seguían otros de apellidos igualmente prestantes, pero cuyas deudas muestran que, de no darse la liberalización de tierras, realmente habrían quedado en la ruina total en la que ya estaban (véase gráfica 2).

Entre otros aspectos del censo en el Estado de Bolívar podemos señalar los siguientes: a) el censo en Cartagena se había estandarizado en $5 \%$, siendo muy pocas las propiedades que se gravaron con un censo mayor; $b$ ) todas las propiedades de la ciudad amurallada de Cartagena estaban gravadas por censos a favor de instituciones afectas a la Iglesia (esto confirma que en el Estado de Bolívar, como en la mayoría de los demás Estados, los bienes raíces se hallaban destinados a alguna obra pía con

${ }^{52}$ Ibid. 


\section{GRÁFICA 2. RELACIÓN DE CENSUALISTAS CON}

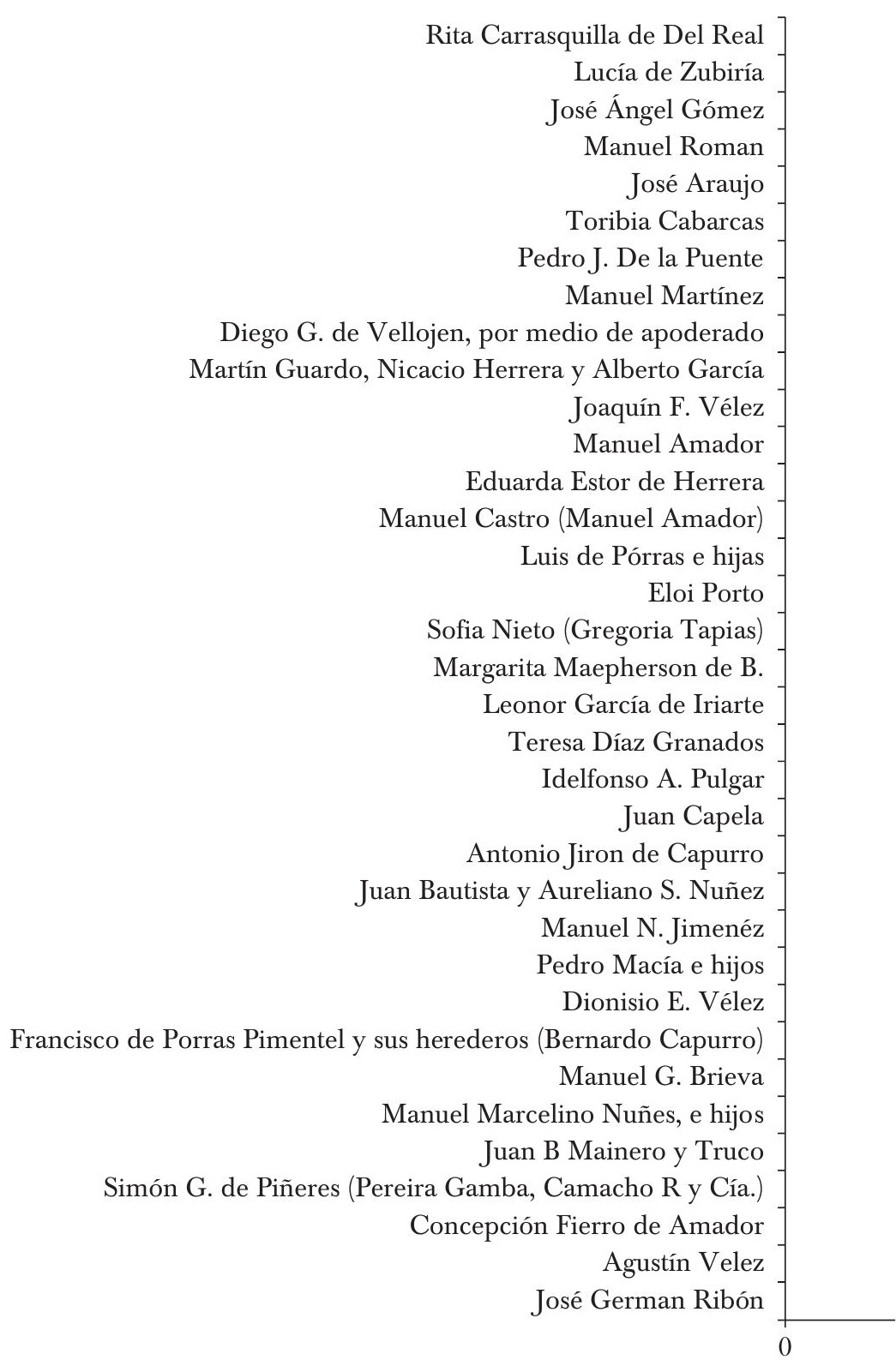

Fuente: elaboración propia con base en Informe, 1865, pp. 1-20. 
CAPITALES DE CENSO ENTRE 12000 Y 2000 PESOS

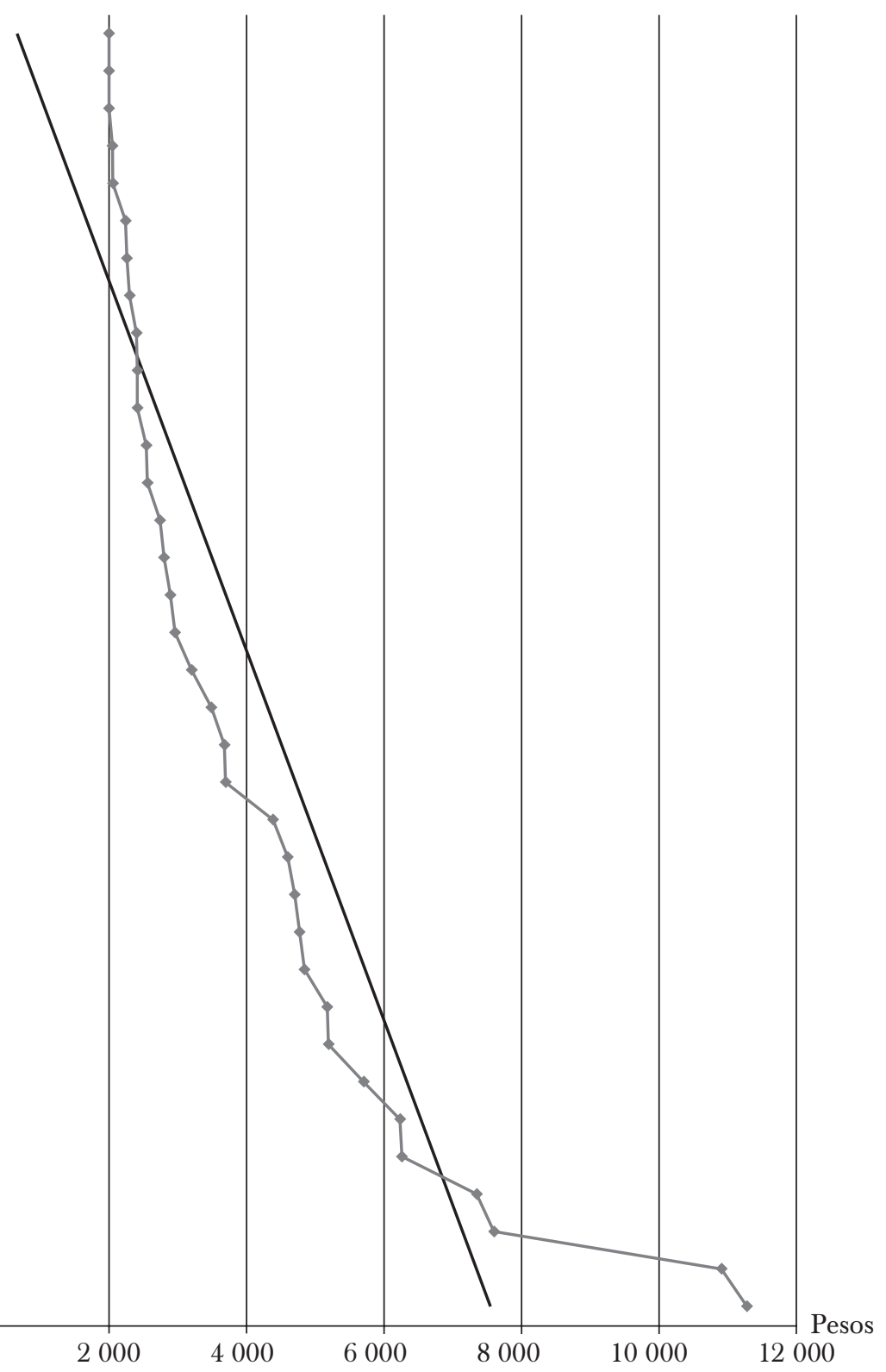


carácter indefinido, lo que los convertía en bienes de manos muertas); c) varios de los censualistas y sus descendientes fueron promotores de las reformas, así como también figuras políticas, ilustrados y comerciantes ${ }^{53}$ en diferentes épocas del Estado. Entre estos se cuentan Manuel Marcelino Núñez, Manuel Narciso Jiménez y Antonio del Real, quienes fueron gobernadores, y Manuel V. Vélez y Manuel Martínez, quienes se desempeñaron como alcaldes en el periodo federalista ${ }^{54} \mathrm{En}$ el mismo sentido puede mencionarse a banqueros como Juan Bautista Mainero y Trucco, director del Banco de Cartagena en 1881, y Pedro Macías Jr., director del Banco de Bolívar en 1874, así como a otros personajes que gozaban de prestancia social en la ciudad.

De acuerdo con el espíritu de la desamortización, específicamente sobre el punto de los censos, el Estado se hizo cargo de las deudas que los particulares tuvieran por este concepto; es decir, recogió los bienes que estaban gravados por censos y los expropió convirtiéndolos de esta manera en propios, para garantizar los derechos del censualista y el censatario. Como lo expusieron los diferentes agentes de la Junta Superior de Bienes Desamortizados, este negocio fue poco productivo ${ }^{55}$ para el Estado de la Unión, ya que aparte de garantizarles los derechos a los particulares, no obtuvo mayores ingresos.

Los pagos a terceros por este concepto (es decir, por fundaciones y capellanías) se llevaron a cabo a través de contratos en los que se intentaba liquidar estos negocios y establecer los créditos de la nación y los de los estados soberanos. Así, en 1870 Esguerra y Córdoba, sociedad en liquidación que representaba al Distrito de Cartagena para dirimir unas cuentas por censo con la Dirección de Impuestos Nacionales, aceptaba que el distrito tenía una deuda con valor de 20451.20 pesos. ${ }^{56}$

La poca eficiencia, las pugnas permanentes y las posiciones radicales entre liberales y conservadores generaron muchas críticas alrededor del tema de la desamortización. Por esta razón, los legisladores de la época consideraron que esta reforma no había producido los efectos económicos esperados. Esta situación involucró a todos los Estados, ya que algunos como la ciudad de Bogotá, ${ }^{77}$ capital de los Estados confederados, fueron

${ }^{53}$ Laverde, Bibliografía, 1895, y Urueta y Gutiérrez, Cartagena, 1912, pp. 288-378.

${ }^{54}$ Urueta y Gutiérrez, Cartagena, 1912, pp. 425-453. Véase también Nieto, Geografía, 1839.

${ }^{55}$ González, Nueva, 1866.

${ }^{56}$ Memoria, 1870, p. 18.

${ }^{57} \mathrm{Al}$ iniciarse el proceso de desamortización, se separaron la inscripción y los remates de bienes de Bogotá de los que se ejecutaron en los nueve estados soberanos, aunque hasta ahora no se ha encontrado documento alguno que haga referencia a esto. A manera de hipótesis, se plantea que ello obedeció, en primer lugar, a que Bogotá era la capital de los estados federados; y en segundo lugar, a que la mayoría de los bienes urbanos en manos muertas estaba concentrada en esta ciudad, la cual aportó, como se planteó anteriormente, $61 \%$ de los bienes desamortizados. 
radicales en la desamortización, mientras otros, como el Estado del Magdalena, prácticamente hicieron caso omiso de la reforma. A su vez, estados como Bolívar, Santander y Panamá se mantuvieron en un término medio; no obstante, esto pudo obedecer a que las cifras de sus reportes posiblemente no correspondían a la totalidad de los bienes existentes. Esta situación se vio reflejada en las notas de los agentes generales de cada periodo en las que se quejaban permanentemente de la negligencia de los Estados en el envío de los respectivos informes, con el consiguiente incremento en la relación de bienes ocultos. Es importante anotar que, en 1910, las casas ubicadas en la ciudad amurallada de Cartagena seguían en manos de los mismos propietarios o de sus descendientes. ${ }^{58}$

\section{Remates, ventas y embargos En CARTAGENa, 1860-1865}

De acuerdo con los procedimientos establecidos, para rematar y subastar los bienes había que cumplir los siguientes pasos: $a$ ) las autoridades o cualquier vecino de la ciudad denunciaba los bienes como de manos muertas; b) el agente del círculo respectivo procedía a inventariarlos luego de convocar al propietario para que demostrara la situación de sus bienes; c) el Estado convocaba a las personas para que pagaran la deuda y adquirieran los mismos bienes según el criterio de propiedad privada individual sobre la tierra; $d$ ) si los interesados no pagaban, se embargaban los bienes; $e$ ) se procedía a la publicación por edicto público; $f$ ) se convocaba al remate, y g) se subastaban los bienes al mejor postor.

$\mathrm{Si}$ bien es cierto que los agentes aglutinaban estos bienes en raíces, muebles, semovientes y censos, en el quinquenio de $1860-1865,{ }^{59}$ en el caso de Cartagena los bienes subastados de particulares gravados por censos a favor de alguna institución eclesiástica estaban representados, fundamentalmente, en casas cuyo avalúo total ascendía a 282571.45 pesos; en capital por censo equivalente a 306417.61 pesos, y en intereses sobre el capital por un total de 65247.07 pesos. De lo anterior se desprende que los préstamos más los intereses (cuyo monto total era de 371664.68 pesos) eran superiores en $24 \%$ al valor de la prenda de garantía que los respaldaba (es decir, al costo real en el mercado de los bienes desamortizados). En consecuencia, la desamortización, desde el punto de vista estrictamente económico, no fue un buen negocio para el Estado, pues al asumir este, a través de la reforma, las deudas del censualista, y al convertirse en garante de pago del censatario, debía cumplirles a ambas partes.

\footnotetext{
${ }^{58}$ Villalba y Cruz, "Propietarios", 2012.

${ }^{59}$ Gaceta Oficial del Estado Soberano de Bolívar, 1860-1865, rollos 769, 770-772 y 774.
} 
Al comparar el avalúo y la deuda, y luego de discriminarla por rangos, tenemos que en el rango de cero a 500 pesos (que comprende a 40 propietarios), la deuda total hasta los 250 pesos aproximadamente se mantuvo por debajo del avalúo y que, a partir de esta cifra, ambos conceptos se equilibran hasta alcanzar los 400 pesos. De ese monto en adelante se observa una tendencia al aumento del capital de censo y a la disminución del avalúo (véase gráfica 3). Por su parte, en el grupo de 500 a 1000 pesos (que comprendió a 31 propietarios) la deuda se incrementa en relación con el avalúo (véase gráfica 4). En el grupo de 1000 a 3 000, la deuda total es ligeramente superior al avalúo total (véase gráfica 5 ).

Del último grupo analizado, es decir, de 3000 a 30000 pesos, se tiene en primer lugar, que resultaba atípico, pues comprendía a tres propietarios cuyas deudas están muy por encima del comportamiento de la deuda del conjunto de propietarios. Esto se debe a que el capital de censo se había adquirido en doblones de oro, el cual, como se observa, era muy superior al avalúo de los bienes raíces que sustentaban la deuda (véase gráfica 6).

$\mathrm{Si}$ se consideran estos grupos desde el punto de vista porcentual en relación con el total de la muestra (que asciende a 148 propietarios-deudo$\left.\operatorname{res}^{60}\right)$, se tiene que el grupo de cero a 500 pesos representa $5 \%$ del total de la muestra en cuanto al avalúo y $3 \%$ en relación con la deuda; el segundo grupo representa $11 \%$ del avalúo y $7 \%$ de la deuda, y el tercer grupo representa $40 \%$ del avalúo y $28 \%$ de la deuda. Por último, el cuarto grupo representa $44 \%$ del avalúo y $62 \%$ de la deuda; de esto se deduce que es en este último grupo donde se encontraba el mayor desfase porcentual entre las dos categorías analizadas (véase gráfica 7).

De los anteriores propietarios, entre los más representativos en cuanto al avalúo de sus bienes estaban Manuel Iriarte, los herederos de José González de Rubio, Manuel M. Núñez y los herederos de Lázaro María Herrera. Entre los que se destacaban por tener las deudas más altas estaban José Merced Barreto, María de Jesús Amador de Arias y Narciso Gómez Guerrero.

Los bienes subastados eran básicamente casas, las cuales se clasificaban en altas y bajas; estas casas, a su vez, podían tener casas accesorias, aljibes o solares. Asimismo, podían estar arruinadas o en mal estado (la

${ }^{60}$ Se excluyen los datos referentes a censos y deudas que no tenían propietario visible; sin embargo, estos datos se contaron en el total de avalúos y censos de capital. En la lista base elaborada para realizar el análisis, se contaron más de 400 propietarios con censo; dicha lista se depuró de acuerdo con los siguientes criterios: $a$ ) un bien se podía publicar para su remate varias veces (en este caso, los agentes, para llevar las cuentas, los iban descontando en la siguiente vigencia fiscal); b) se excluyeron los bienes que no estaban dentro de la ciudad amurallada (debido a que esta investigación tiene como objeto realizar el análisis de los que estaban dentro de los límites de esta, quedaron por fuera los barrios extramuros y bienes ubicados en Mamonal, Turbaco, Mompox, Magangué y El Cabrero, entre otros); c) en el caso de los bienes subastados varias veces, se tomó como referencia el valor del capital censado y el avalúo del último año referenciado. 
GRÁFICA 3. COMPARACIÓN ENTRE AVALÚO Y DEUDA ENTRE 0 Y 500 PESOS

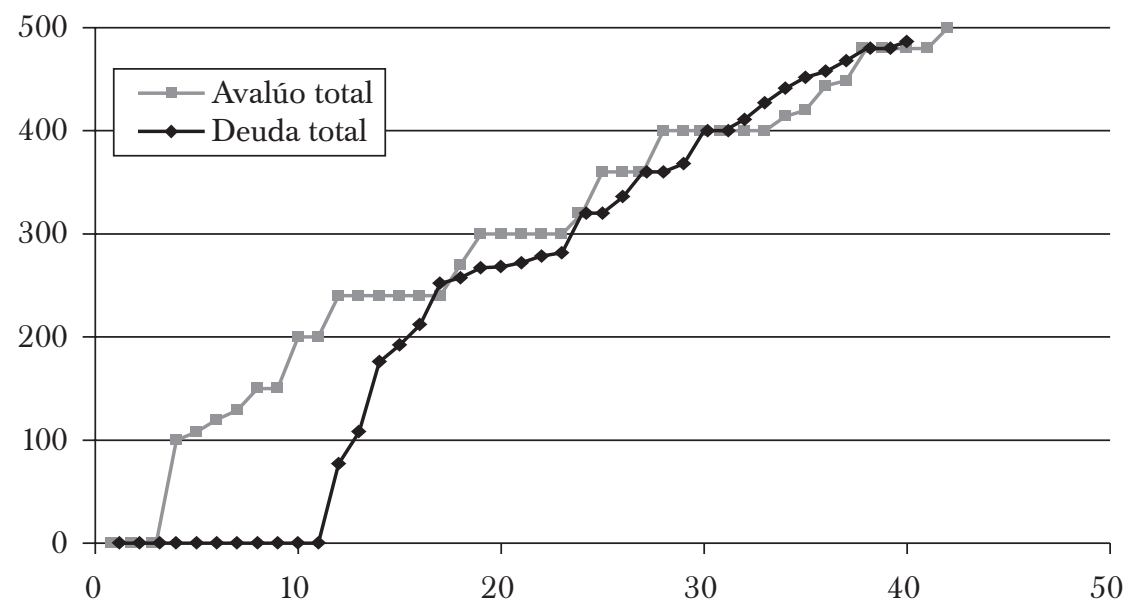

Fuente: elaboración propia con base en Informe, 1865, pp. 1-20.

\section{GRÁFICA 4. COMPARACIÓN ENTRE AVALÚO Y DEUDA}

DE 500 A 1000 PESOS

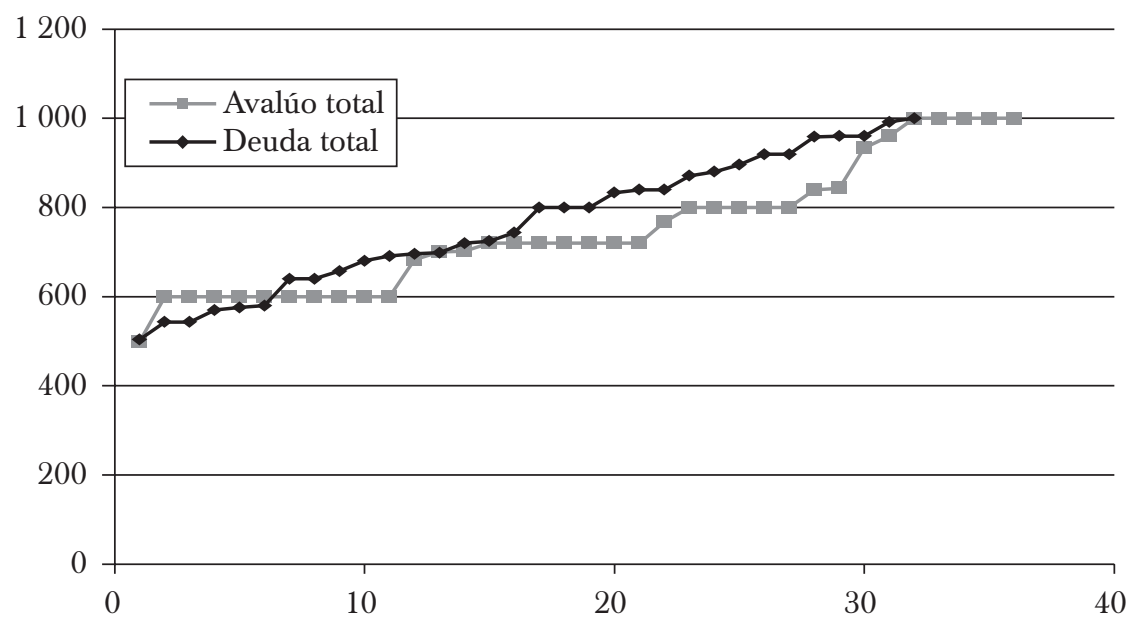

Fuente: elaboración propia con base en Informe, 1865, pp. 1-20. 


\section{GRÁFICA 5. COMPARACIÓN ENTRE AVALÚO Y DEUDA}

DE 1000 A 3000 PESOS

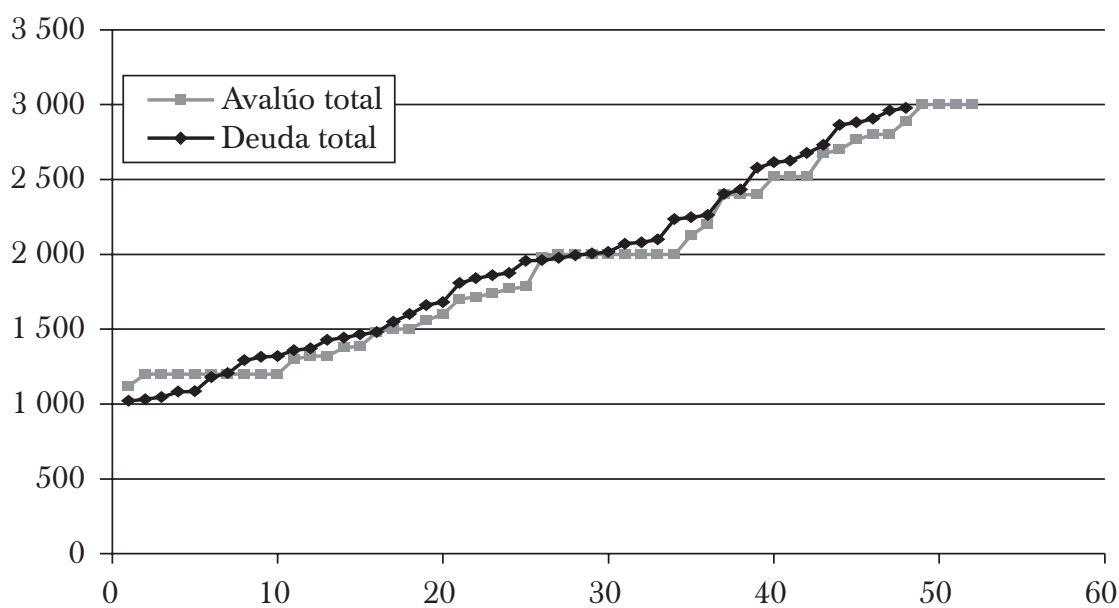

Fuente: elaboración propia con base en Informe, 1865, pp. 1-20.

GRÁFICA 6. COMPARACIÓN ENTRE AVALÚO Y DEUDA

DE 3000 A 30000 PESOS

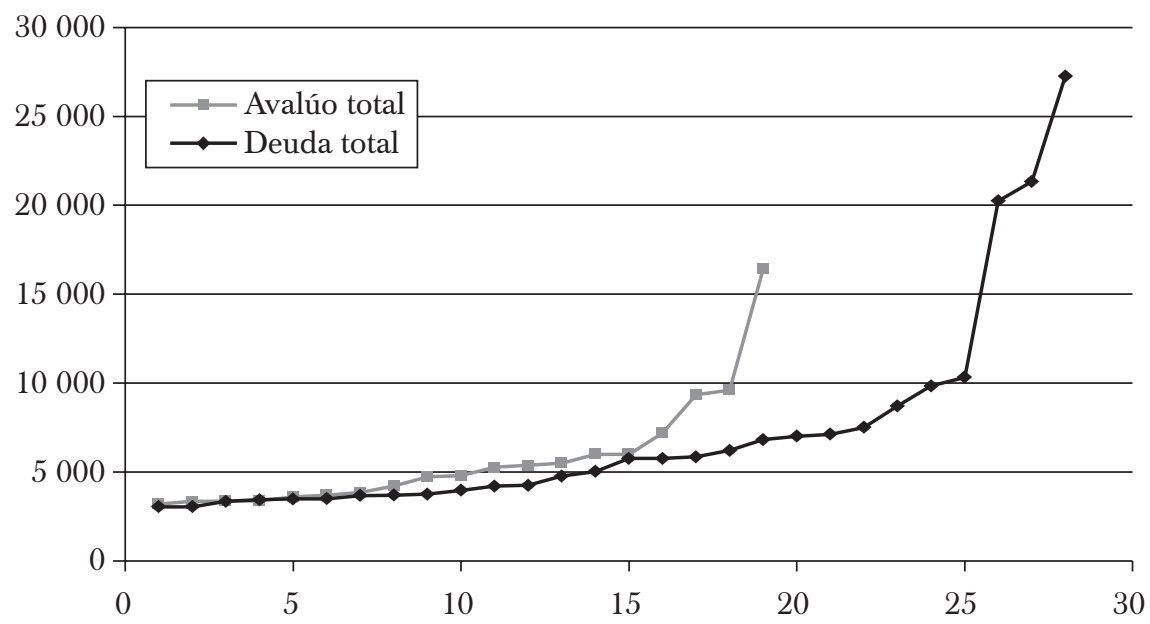

Fuente: elaboración propia con base en Informe, 1865, pp. 1-20. 


\section{GRÁFICA 7. RELACIÓN PORCENTUAL DE LAS DEUDAS POR CAPITAL Y AVALÚOS}
AVALÚO
DEUDA
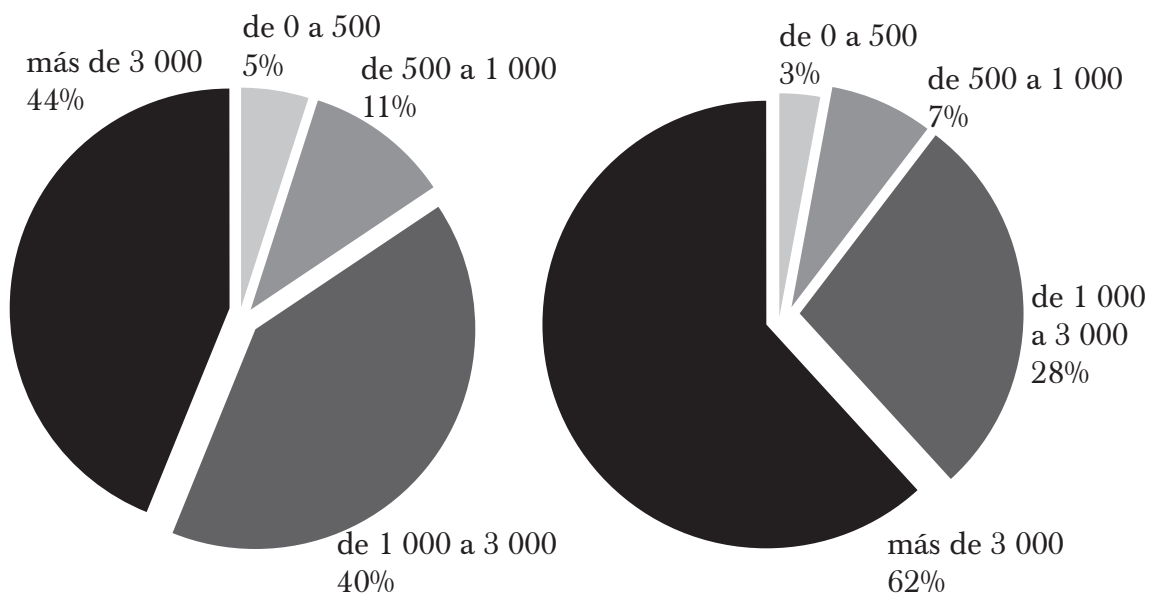

Fuente: elaboración propia con base en Diario de Bolívar, 1860-1865.

importancia de la descripción del estado del inmueble radicaba en que permitía determinar su precio de venta). En total, se pusieron en remate 214 casas, $51^{61}$ solares y una tienda con altillo (véase cuadro 7).

En cuanto a los valores, se observa que el avalúo total de las casas altas (desagregadas) ascendía a 142875.68 pesos y tenían deudas por censo de 188613.74 pesos. Por su parte, las casas bajas (desagregadas) estaban valuadas en 93132.57 pesos y su deuda de capital a censo más intereses era de 124844.02 pesos.

Las casitas, a su vez, estaban valuadas en 6500 pesos, pero no se tienen datos de los censos a los que estaban sometidas; cabe mencionar que a pesar de que se denominaban "casitas", su precio no estaba por debajo del de las casas altas ni de las casas bajas. Los solares referidos tenían un avalúo de 16830 pesos y una deuda por 23586.47 pesos; si se analiza la relación avalúo-deuda en este caso, se observa que se mantiene la tendencia de los propietarios a tener más deudas que valor en bienes. Atendiendo

${ }^{61}$ Este total incluye los que estaban valuados por separado y dos casos de casas antiguas de las que solamente quedaba el solar. 


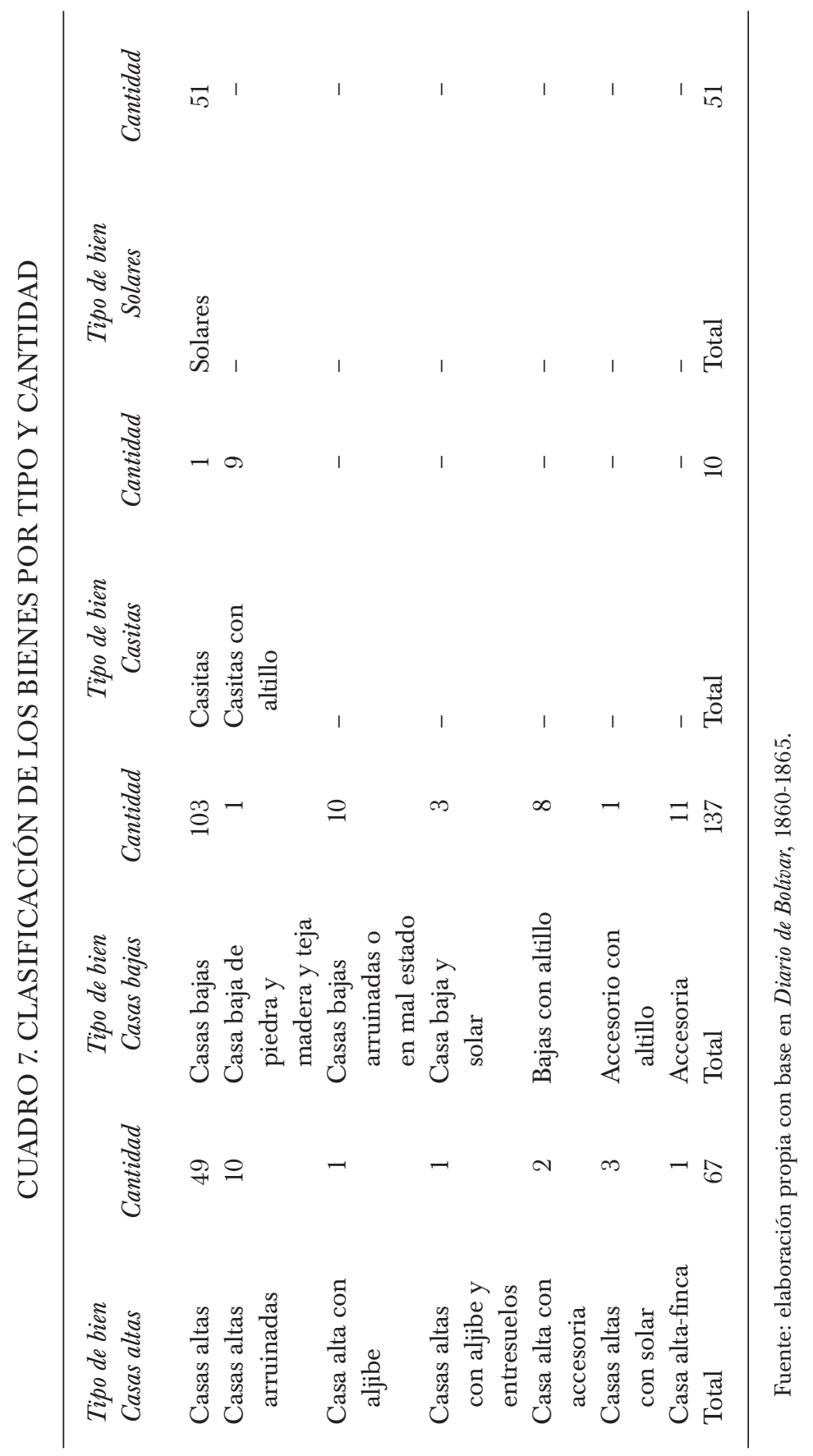


los remates por año, ${ }^{62}$ se encuentra que en 1862 se remataron 84 casas (es decir, al comienzo de la desamortización), seguido de los años 1863 (42 remates) y 1864 (con 38 remates). Los demás años se mantuvieron en un promedio de quince remates anuales.

De acuerdo con la ubicación de los bienes raíces, se observa que el mayor número de casas se remató en la plaza de Santo Toribio en intersección con las calles aledañas. En total, allí se remataron once bienes, valuados en 16800 pesos y con un capital de censo de 17554.81 pesos. Le siguen la calle Larga, con once bienes valuados en 10735 pesos y un censo de capital de 15936.66 pesos; la calle de la Iglesia, con siete bienes valuados en 6800 pesos y un censo de capital de 1600 pesos; la calle de San Andrés, con seis bienes, y las calles de las Bóvedas, del Sargento Mayor y de la Moneda, con cinco bienes cada una. Sin embargo, si se analiza el valor del avalúo, se tiene que en la calle del Cuartel se remató una casa valuada en 9600 pesos con un censo de capital de 9838.10 pesos, una casa en la calle de Santa Teresa por 6000 pesos y otra en la calle de San Juan por 5600 pesos.

En relación con la procedencia de los bienes incluidos en la gráfica 8, se aprecia que la mayoría provenía del Monasterio de Santa Clara (36\%), es decir, propiedades que por vía de censo le estaban adscritas. Les siguen los bienes procedentes del Capítulo Catedral, los cuales son significativos pero están por debajo de la mitad de los pertenecientes al monasterio de Santa Clara. Se trata de bienes que por medio de la desamortización habían pasado al Estado de Bolívar, mientras que otros pasaron a la nación ya entrado el siglo Xx. ${ }^{63}$

Entre las rentas más representativas pertenecientes al Estado ${ }^{64}$ se cuentan las del hospital de Caridad, que ascendían a 78252.82 pesos, que recaudaban por réditos la suma de 4335.09 pesos y cuyas cuentas se desagregaron (véase cuadro 8).

Según la división anterior, se puede observar que la mayoría de los bienes pertenecientes al hospital procedían de bienes de particulares $(53 \%)$ que se hallaban censados a 5\%; estos, a su vez, eran los que más intereses producían anualmente (48\% de lo captado).

El hospital también poseía fincas que estaban libres de censo, pero que producían rentas anuales; de ello se deduce que se hallaban arrendados, considerando que se referían a dos solares, una finca, ocho casas y una tienda. Dentro de las cifras que se pueden destacar de bienes de particulares censados a favor del hospital y ubicadas intramuros tenemos

\footnotetext{
${ }^{62}$ Muchas de las casas se vendían con el solar contiguo.

${ }^{63}$ Para un inventario de los bienes nacionales, departamentales y municipales que seguían concentrados en el departamento de Bolívar hasta 1898, véase Compilación, 1898.

${ }^{64}$ Gaceta Oficial del Estado Soberano de Bolívar, 1860, núm. 146, pp. 3-4.
} 


\section{GRÁFICA 8. PORCENTAJE DE LOS REMATES DE ACUERDO CON SU PROCEDENCIA}

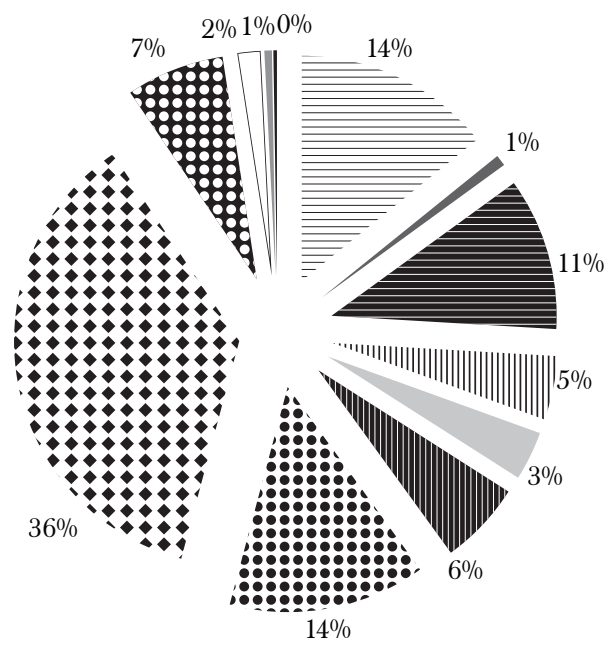

$\equiv$ Procedentes del Colegio de Bolívar - Procedentes del Colegio Seminario E Procedentes de la Casa de obra pía, Hospital de mujeres

III Procedentes del Hospital de Caridad y Casa de Beneficencia

Procedentes del Patronato de la Mitra

IIII Procedentes de la Parroquia de la Catedral

:: Procedentes del Capítulo Catedral

: Procedentes del Monasterio de Santa Clara

* Procedentes del Monasterio de Santa Teresa

$\square$ Procedentes del Hospital del Lazareto

- Procedentes de la Cofradía del Santísimo

- Procedentes de la Hermandad del Buen Viaje

Fuente: elaboración propia con base en Diario de Bolívar, 1860-1865.

CUADRO 8. CUENTAS DE LAS RENTAS DEL HOSPITAL DE CARIDAD

Concepto

Certificación de censo sobre el tesoro de la confederación

Documentos de renta sobre el tesoro de la confederación

Concejo Municipal de Cartagena sobre sus ventas

Censos a $5 \%$ sobre fincas de particulares
Capital

Rédito

12141

607.05

20731

1122.45

4114.20

205.71

$41266.62 \quad 2605.59$

Fuente: elaboración propia con base en Gaceta Oficial del Estado Soberano de Bolívar, 6 de mayo de 1860 , rollo 769 , pp. 3-4. 
a Isabel Ruiz, con cinco casas bajas en la calle del Espíritu Santo (3 128.23 pesos), y a Bernardo Capurro, Enrique J. Matos, herederos de Enrique P. de la Vega, herederos de Carlos Jiménez, Pedro Macías, Juan de Francisco Martín, Antonio María de Zubiría y herederos de Rafael N. Hurtado, con un capital que oscilaba entre los 1000 y los 1500 pesos.

Por otra parte, la participación del Estado de Bolívar en el ramo de bienes desamortizados reportados a la Hacienda nacional fue de 1183885.47 pesos y los bienes puestos en subastas de la ciudad de Cartagena, entre 1860 y 1865, fueron del orden de 654236.13 pesos, equivalentes a una ejecución de 55.2\% del total desamortizado en el Estado.

\section{CONCLUSIÓN}

Sobre este tema tenemos que la desamortización de bienes de manos muertas, como la reforma más importante sobre la trasformación de la propiedad en el siglo XIX, en Bolívar se comportó de acuerdo con la tendencia nacional; sin embargo, en cuanto a los remates, el Estado adoptó una posición bastante cauta.

En relación con los embargos, remates y subastas, se observa que su ejecución encontró numerosos obstáculos, pues, aunque legalmente se procediera según la ley, en muchos casos no había demandantes para los bienes; de allí que fuera necesario publicarlos entre tres y once veces para poder concretar el remate. Esta situación obedecía a que los bienes que se ponían en remate eran los gravados por censos, que, en el caso señalado, pertenecían a las familias más destacadas, las cuales no tenían solvencia económica para readquirirlos inmediatamente.

Puede decirse que el periodo estudiado, 1861-1865, coincidió con el auge de la reforma, pues en esos años se ejecutó más de 50\% de las subastas de los bienes reportados. En cuanto a los tipos de bienes, tenemos que eran básicamente casas y algunos solares. Esto resulta de importancia en la medida en que se sabe que dichos bienes pasaron al Estado, el cual se convirtió en el garante de la deuda para respaldar el negocio hacia ambas partes, es decir, el censualista y el censatario.

Para finalizar, tenemos que esta reforma tendió a liquidar las antiguas estructuras coloniales con el fin de poner a circular todos los bienes en un mercado libre. Con esto se pretendía promover el crecimiento de la industria y, por lo tanto, la consolidación del desarrollo y el progreso, con el objeto de darle el impulso necesario a una economía de corte liberal. No obstante, los recaudos no se correspondieron con los ingresos esperados por la Hacienda nacional, pues desde el punto de vista estrictamente financiero fue una reforma en la que la nación no sólo perdió propiedades (representadas en 
casas y tierras, entre otras), sino que además, por la compleja estructura de este ramo, motivó la corrupción entre sus funcionarios y la reconcentración de bienes en manos de los que ya los poseían de tiempo atrás.

\section{FUENTES CONSULTADAS}

\section{Hemerografía}

Gaceta de Bolivar, Cartagena, Colombia.

Gaceta Oficial del Estado Soberano de Bolivar, Cartagena, Colombia.

\section{Bibliografía}

BazAnt, Jan, Los bienes de la Iglesia en México (1856-1875). Aspectos económicos y sociales de la revolución liberal, México, El Colegio de México, 1971.

CAmacho Roldán, SAlvador, Escritos sobre economía y política, Bogotá, Instituto Colombiano de Cultura, 1976.

Campomanes Rodríguez, Pedro D., Tratado de la regalía de amortización, Madrid, Imprenta Real de la Gaceta, 1765.

Codazzi, Agustín, Manuel María Paz y Felipe Pérez, Atlas geográfico e histórico de la República de Colombia (Antigua Nueva Granada), París, A. Lahure, 1889, en $<$ http://commons.wikimedia.org/wiki/File:Territorios_de_Colombia_entre_1843 _y_1886.jpg $>$. [Consulta: junio de 2013.]

Compilación de documentos referentes a los bienes del departamento y a otros asuntos del ramo de Hacienda, Cartagena, Imprenta El Esfuerzo, 1898.

CORTÉs, José DAVID, "Desafuero eclesiástico, desamortización y tolerancia de cultos: una aproximación comparativa a las reformas liberales mexicana y colombiana de mediados del siglo XIX”, Fronteras de la Historia, Instituto Colombiano de Antropología e Historia, vol. 9, 2004, pp. 93-128.

Cruz Vergara, Maribel de la, "El proceso de liberalización de tierras en Colombia en el siglo XIX. El Estado Soberano de Bolívar”, tesis doctoral, Sevilla, 2012, inédito. , "El proceso jurídico político de la desamortización de bienes de manos muertas en Colombia, 1766-1887", Taller de la Historia, Universidad de Cartagena, 2009, vol. I, núm. 1.

Decreto reglamentando la administración de los bienes desamortizados, Bogotá, Imprenta de la Nación, Biblioteca Luis Ángel Arango del Banco de la República, miscelánea $1445,1864$.

DíAz Díaz, Fernando, La desamortización de bienes eclesiásticos en Boyacá, Tunja, Imprenta Tunja/Universidad Pedagógica y Tecnológica de Colombia, 1977. 
, "Estado, Iglesia y desamortización” en Jaime Jaramillo Uribe (dir.), Nueva historia de Colombia, Bogotá, Planeta, 1989, pp. 197-222.

El monitor, o la guerra de la religión, Bogotá, Imprenta de la Nación, miscelánea 1266, pieza 5, 1861, pp. 1-3.

Estadística de Colombia, Bogotá, Imprenta de Medardo Rivas, 1876.

Exposición católica o principios y reglas de conducta de los católicos en la situación actual de la Iglesia neogranadina, Bogotá, Imprenta de Torres Amaya, 1853.

GonzÁlez, Fernán, Poderes enfrentados: Iglesia y Estado en Colombia, Bogotá, Centro de Investigación y Educación Popular, 1977.

, "Iglesia y Estado desde la convención de Rionegro hasta el Olimpo Radical, 1863-1878”, Anuario Colombiano de Historia Social y de la Cultura, Universidad Nacional de Colombia, vol. 15, 1987, pp. 91-163, en <http://www.banrepcultural. org/blaavirtual/revistas/revanuario/indice.htm>. [Consulta: enero de 2007.]

GonZÁlez, NARCISO, Nueva rectificación de hechos, sobre la cuestión de remates, Bogotá, Imprenta de Gaitán, Biblioteca Luis Ángel Arango del Banco de la República, miscelánea 1445, pieza 5, 1866.

Grande escándalo: que tuvo lugar en la noche del 30 de octubre del presente año en la sesión de la Escuela Republicana (alias comunista), Bogotá, Imprenta de Espinosa, miscelánea 1505, pieza 49, 1850.

Groot, José Manuel, Historia eclesiástica y civil de la Nueva Granada, Bogotá, Imprenta de Medardo Rivas, 1869-1870.

Hera, Alfredo de la, "Precedentes ilustrados del proceso desvinculador y desamortizador de bienes de manos muertas" en Prien y Martínez de Codes, Proceso, 1999, pp. 77-96.

Informe del agente general de bienes desamortizados, 1865, Bogotá, Imprenta El Mosaico, Biblioteca Luis Ángel Arango del Banco de la República, miscelánea 1445, pieza 4, 1865.

Informe del agente general de bienes desamortizados, 1867, Bogotá, Imprenta de Gaitán, Biblioteca Luis Ángel Arango del Banco de la República, Sala de Libros Raros y Manuscritos, miscelánea 1445, 1867.

Informe del agente general de bienes desamortizados, 1869, Bogotá, Imprenta de Gaitán, Biblioteca Luis Ángel Arango del Banco de la República, Sala de Libros Raros y Manuscritos, miscelánea 1445, 1869.

Informe del agente general de bienes desamortizados, 1874, Bogotá, Imprenta de Echeverría Hermanos, Biblioteca Luis Ángel Arango del Banco de la República, Sala de Libros Raros y Manuscritos, miscelánea 1445, 1874.

Informe del agente general de bienes desamortizados, 1875, Bogotá, Imprenta de Echavarría Hermanos, Biblioteca Luis Ángel Arango del Banco de la República, Sala de Libros Raros y Manuscritos, miscelánea 1445, 1875.

Informe del agente general de bienes desamortizados, 1876, Bogotá, Imprenta de Gaitán, Biblioteca Luis Ángel Arango del Banco de la República, Sala de Libros Raros y Manuscritos, miscelánea 1445, 1876. 
Jaramillo, Roberto Luis y Adolfo Meisel Roca, "Más allá de la retórica de la reacción. Análisis económico de la desamortización en Colombia, 1861-1888” en Adolfo Meisel Roca y María Teresa Ramírez (eds.), Economía colombiana del siglo XIX, Colombia, Fondo de Cultura Económica, 2010.

Jovellanos, Gaspar Melchor De, Obras de don Gaspar Melchor de Jovellanos, Madrid, F. de P. Mellado, 1845.

Knowlton, Robert J., "Expropriation of Church Property in Nineteenth-Century México and Colombia. A Comparison", The Americas, Academy of American Franciscan History, vol. 25, núm. 4, abril de 1969, pp. 387-401, en <http://www. jstor.org/stable/980320>. [Consulta: abril de 2013.]

Laverde Amaya, Isidoro, Bibliografía colombiana, Bogotá, Medardo Rivas, 1895 (Colección Biografías, Biblioteca Virtual Luis Ángel Arango), en <http://www. banrepcultural.org/blaavirtual/bibliografias/bicol/bicol/bicol05.htm $>$. [Consulta: mayo de 2013.]

Levaggi, Abelardo, "El proceso desamortizador y desvinculador de los bienes de manos muertas desde la óptica jurídica” en Prien y Martínez de Codes, Proceso, 1999, pp. 33-60.

Manifestación y protestas que hacen las M. R. M. M. monjas del monasterio de Nuestra Señora del Carmen de Santafé de Bogotá, Cartagena, Imprenta de Federico Núñez, Biblioteca Luis Ángel Arango del Banco de la República, Sala de Libros Raros y Manuscritos, miscelánea 1505, 1863.

Martínez de Codes, Rosa María, "Luces y sombras de un proceso de larga duración” en Prien y Martínez de Codes, Proceso, 1999, pp. 7-32.

Meisel Roca, Adolfo e Irene Salazar Mejía, "La desamortización en el Caribe colombiano: una reforma urbana liberal, 1861-1881", Historia Caribe, Universidad del Atlántico, vol. viI, enero-junio de 2012, pp. 119-146.

Memoria del secretario del Tesoro y Crédito Nacional al Congreso de 1870, Bogotá, Imprenta de Medardo Rivas, 1870.

Memoria del secretario del Tesoro y Crédito Nacional al Congreso de 1871, Bogotá Imprenta de la Nación, 1871.

Memoria dirigida al ciudadano presidente de los Estados Unidos de Colombia, para presentarla al Congreso Federal, en sus sesiones ordinarias de 1872, Bogotá, Imprenta de Medardo Rivas, 1872.

Memoria presentada al presidente de los Estados Unidos de Colombia por el secretario del Tesoro y Crédito Nacional, 1873, Bogotá, Imprenta de Gaitán, Biblioteca Luis Ángel Arango del Banco de la República, Sala de Libros Raros y Manuscritos, miscelánea $1371,1873$.

Moñino, José, Conde de Floridablanca, Obras originales del conde de Floridablanca, B. A. E. LIX, Madrid, Rivadeneyra, 1867.

Nieto, JuAn José, Geografía histórica, estadística y local de la provincia de Cartagena, república de la Nueva Granada, descrita por cantones, Cartagena, Imprenta de Eduardo Hernández, 1839. 
Bosquejo histórico de la revolución que regeneró al Estado de Bolívar, Cartagena, Imprenta de Ruiz e Hijos, 1862.

Opúsculo en defensa del matrimonio indisoluble, homenaje de respeto a las vírgenes, de justicia a las señoras casadas, de la Nueva Granada, Bogotá, Imprenta de Nicolás Gómez, Biblioteca Luis Ángel Arango del Banco de la República, Sala de Libros Raros y Manuscritos, miscelánea 3125, 1854.

PÉREZ, FELIPE, Geografía general, física y política de los Estados Unidos de Colombia y geografía particular de la ciudad de Bogotá, Bogotá, Imprenta de Echeverría Hermanos, 1883.

Piel, Jean, "Problemática de las desamortizaciones en Hispanoamérica en el siglo XIX (algunas consideraciones desde el punto de vista socioeconómico y, por tanto, ideológico)" en Prien y Martínez de Codes, Proceso, 1999, pp. 97-128.

Pombo, Manuel y José JoaQuín Guerra, Constituciones de Colombia, Bogotá, Biblioteca Banco Popular, 1986.

Preston Hyland, Richard, El crédito y la economía, 1851-1880, Bogotá, Fondo de Cultura Económica, 1983, t. IV.

Prien, Hans-Jürguen y Rosa María Martínez de Codes (coords.), El proceso desvinculador y desamortizador de bienes eclesiásticos y comunales en la América española, siglos XVIII y XIX, Países Bajos, Asociación de Historiadores Latinoamericanistas Europeos/Ridderkerk, 1999 (Cuadernos de Historia Latinoamericana, núm. 7).

Recopilación de las disposiciones fundamentales $i$ reglamentarias sobre crédito nacional $i$ desamortización de bienes de manos muertas: Decreto de 9 de setiembre de 1861, Biblioteca Luis Ángel Arango del Banco de la República, Sala de Libros Raros y Manuscritos, miscelánea 1266 , pieza 7, 1862.

Restrepo, Juan Pablo, La Iglesia y el Estado en Colombia, Bogotá, Biblioteca Banco Popular, 1987, t. I.

Restrepo Piedrahíta, Carlos, Constituciones de la primera república liberal, Bogotá, Universidad Externado de Colombia, 1985, tt. I-IV.

SCHENK, Frank, "Muchas palabras, poca historia: una historiografía de la desamortización de las tierras comunales en México (1856-1911)" en Prien y Martínez dE Codes, Proceso, 1999, pp. 215-227.

Urueta, José P. y Eduardo Gutiérrez de Piñeres, Cartagena y sus cercanías. Guía descriptiva de la capital del departamento de Bolívar, prólogo de Alfonso Múnera Cavadía, Cartagena, Biblioteca Bicentenario de la Independencia de Cartagena, 1912.

Villalba, José y Maribel de la Cruz Vergara, "Propietarios en el sector amurallado de Cartagena en 1910”, Cartagena de Indias, Universidad de Cartagena, 2012, inédito.

Villegas, Jorge, Enfrentamientos Estado e Iglesia. 1819-1887, Medellín, Universidad de Antioquia, 1977.

Wobeser, Gisela Von, "El origen y la finalidad que se perseguía con el real decreto sobre enajenación de bienes eclesiásticos (consolidación) en América en 1804” en Prien y Martínez de Codes, Proceso, 1999, pp. 189-214. 